\title{
The Effect of Additive Chemical Structure on the Tribofilms Derived from Varying Molybdenum-Sulfur Chemistries
}

\author{
Aaron L. Barnes ${ }^{1}$ (D) $\cdot$ Ardian Morina $^{1}$ (D) $\cdot$ Rhiann E. Andrew $^{2}$ (D) $\cdot$ Anne Neville $^{1}$ (D)
}

Received: 30 July 2020 / Accepted: 30 July 2021 / Published online: 15 September 2021

(c) The Author(s) 2021

\begin{abstract}
Molybdenum disulfide $\left(\mathrm{MoS}_{2}\right)$ is an effective friction modifier that can be formed on surfaces from oil-soluble lubricant additives. Different additive chemistries can be used to form $\mathrm{MoS}_{2}$ on a surface. The tribofilms formed from three different molybdenum additives (MoDTC Dimer, MoDTC Trimer, and molybdate ester) were studied in additive monoblends and fully formulated systems. The resulting tribofilms were then characterized by Raman spectroscopic spatial mapping, XPS, and FIB-TEM. The distribution of $\mathrm{MoS}_{2}$ on the surface was much more sparse for the molybdate ester than the other additives. No crystalline molybdenum oxides were observed by Raman spectroscopy, but their presence was inferred from XPS analysis. XPS analysis showed very similar distributions of Mo oxidation states from each additive, such that the chemical nature of the films formed from all of the additives is likely similar. Each of the additive tribofilms was observed to have $\mathrm{MoS}_{3}$ vibrations in Raman and persulfide XPS peaks associated with amorphous $\mathrm{MoS}_{3}$, as such this species is presented as a common frictional decomposition product for all the additives. The MoDTC trimer is more able to produce this amorphous species on the contacting surfaces due to its structural similarities to the co-ordination polymer $\mathrm{MoS}_{3}$.
\end{abstract}

Aaron L. Barnes

mnalba@leeds.ac.uk

1 Institute of Functional Surfaces, School of Mechanical

Engineering, University of Leeds, Woodhouse Ln,

Leeds LS2 9JT, UK

2 Infineum UK Ltd., Milton Hill, Abingdon OX13 6BB, UK 


\section{Graphical Abstract}

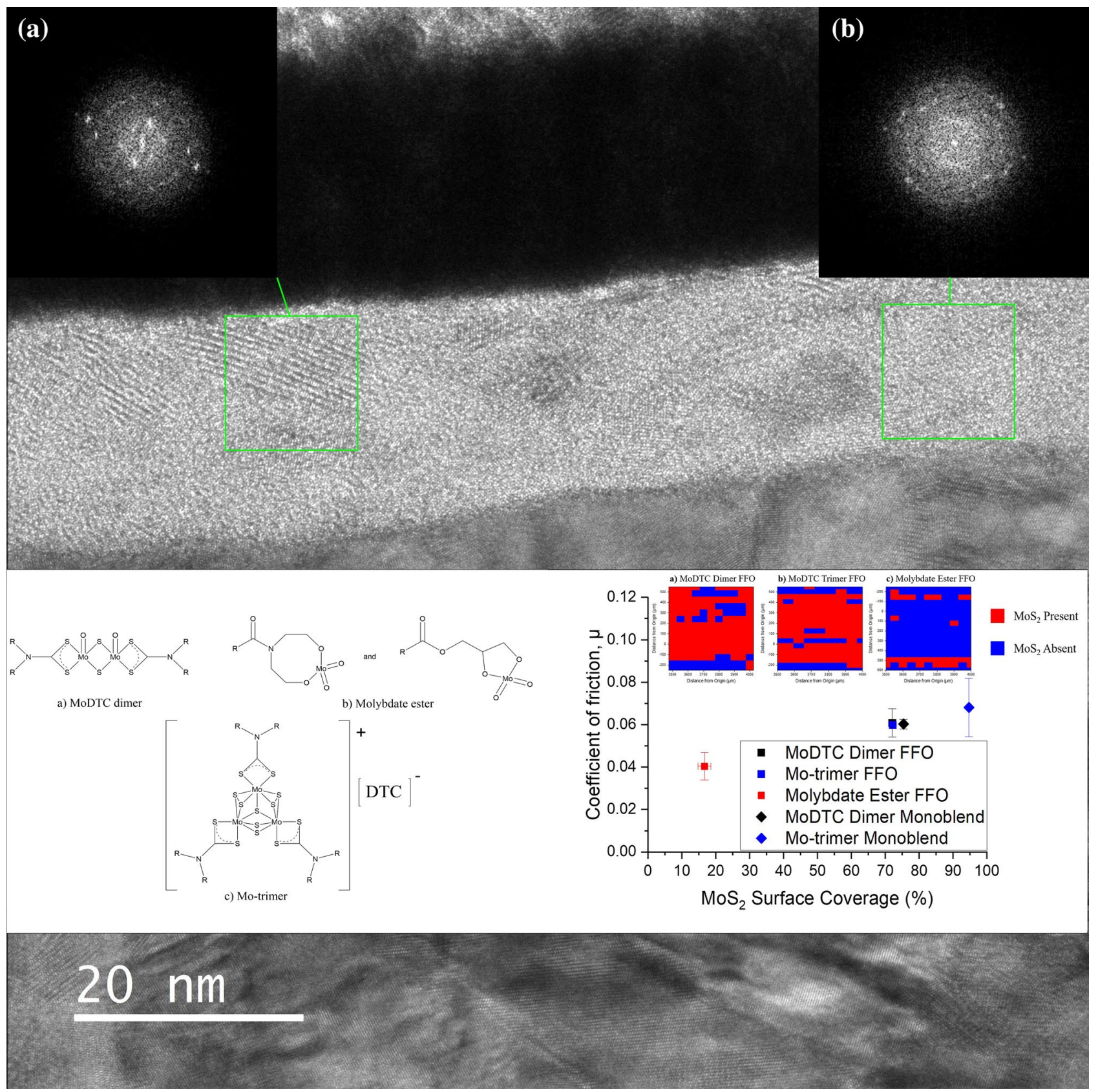

Keywords Additive decomposition $\cdot$ Friction modifiers $\cdot$ Boundary lubrication chemistry $\cdot$ TGA $\cdot$ Raman $\cdot$ XPS

\section{Introduction}

In mechanical contacts, there is always a fraction of energy input lost to friction. Automotive engines contain many such contacts, and their cumulative frictional losses adversely impact fuel efficiency. The reduction of this energy wastage is a target for both improving fuel economy and reducing emissions [1-3].

In automotive lubricant formulations, oil-soluble molybdenum-sulfur compounds have been utilized for many years to form the insoluble, low-friction lattice material molybdenum disulfide $\left(\mathrm{MoS}_{2}\right)$ in situ. The layered crystal structure of $\mathrm{MoS}_{2}$ consists of stacked, trigonal prismatic 
molybdenum-sulfur sheets [4]. There is strong covalent bonding between the molybdenum and sulfur atoms within a sheet but only weak Van Der Waals forces acting between sheets, which easily shear over one another in boundarylubricated contacts [5].

Molybdenum disulfide can be formed from a variety of different additive chemical structures, either through decomposition of the additive molecules themselves or through interaction with other additives in a lubricant formulation. Common molybdenum friction modifier additives include the molybdenum dialkyldithiocarbamate (MoDTC) dimeric structure (Fig. 1a), MoDTC trimers (Fig. 1c), and sulfur-free molybdate esters (Fig. 1b).

The majority of research in the field of molybdenum-sulfur friction modifiers has centered on the MoDTC dimeric structure [6-10]. This additive contains both sulfur and oxygen, with a range of degrees of oxidation, depending on synthesis and thermal oxidation of the additive structure [9, 10]. The MoDTC dimer is able to form $\mathrm{MoS}_{2}$ in base oil, without requiring other additive interactions. Grossiord et al. [11] proposed that the MoDTC dimer decomposes through a mixed molybdenum oxysulfide, which decomposes further to form crystalline $\mathrm{MoS}_{2}$ and molybdenum oxides [12]. Raman analysis of MoDTC dimer wear scars has struggled to confirm the presence of molybdenum oxides, except under high-temperature conditions or laser-induced film oxidation $[6,7,13]$. However, evidence has been found by Raman for the formation of iron molybdate species such as $\mathrm{FeMoO}_{4}$ by Okubo [14] and Khaemba [15] which might act as a candidate for a potential oxygenated decomposition product in place of molybdenum oxides. In addition, Khaemba proposed that the decomposition of MoDTC dimers proceeds in a two-step mechanism [15]. The first step involves the tribologically activated conversion of the MoDTC dimer molecule to amorphous $\operatorname{MoS}_{\mathrm{x}}$, followed by formation of $\mathrm{MoS}_{2}$ from this intermediate, dependent on temperature, shear stress, and MoDTC dimer concentration.

Some studies have determined the friction performance of this additive in tandem with a MoDTC trimer structure (Fig. 1c), which has improved antioxidant properties relative to the MoDTC dimer [16-19]. This has led to its inclusion in oil formulations to extend the friction-reducing lifetime of a lubricant relative to MoDTC dimer alone [20-22]. Like the MoDTC dimer, the MoDTC trimer is able to form $\mathrm{MoS}_{2}$ dissolved alone in base oil. As the MoDTC trimer is often used as a comparative reference to the MoDTC dimer, there has been less interest in determining its specific decomposition mechanism relative to MoDTC dimer. Pawlicki et al. [23] have proposed from simulations that the MoDTC trimer decomposes through formation of a three-dimensional network of layered trimer molecules which form pseudo- $\mathrm{MoS}_{2}$ nanostructures. The MoDTC trimer is a sulfur-rich species with less oxygen content than the MoDTC dimer. As the most sulfur rich of the commonly studied additive species, this additive may be more easily able to decompose to form molybdenum sulfides than the MoDTC dimer. In commercial formulations, the MoDTC trimer exists as a range of trimeric Mo:S cores, the major component of which is shown in Fig. 1c [21, 24]. The friction coefficients of films derived from the MoDTC trimer have been comparable with those

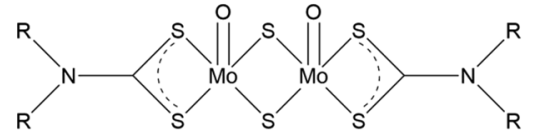

(a) MoDTC dimer<smiles>[R]C(=O)N1CCO[W](=O)(=O)OCC1</smiles>

(b) Molybdate ester

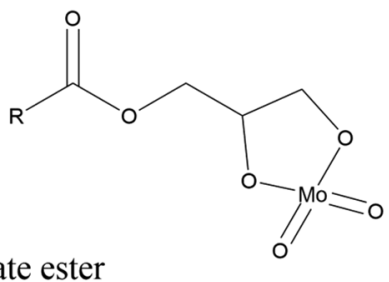

$[\text { DTC }]^{+}$

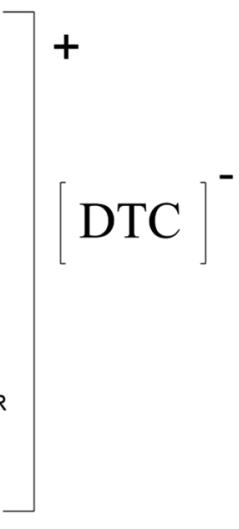

(c) Mo-trimer

Fig. 1 Molybdenum additives used in this study, a MoDTC dimer, b Molybdate ester, $\mathbf{c}$ MoDTC trimer 
of the MoDTC dimer, dependent on the surface chemistry and contact conditions $[16,17,19]$.

Environmental regulations have provided increased motivation to reduce the sulfur content of oils. This has led to renewed interest in formulations containing sulfur-free molybdates initially developed in the 1960s [25-28]. Molybdate ester structures of the type used in this study do not contain sulfur. They exist as oxygenated molybdenum species with a Mo (VI) center bonded to four oxygen atoms. Sulfurfree molybdates form $\mathrm{MoS}_{2}$ in tribological contacts through interactions with sulfur-containing additives in a formulation such as zinc dialkyl dithiophosphates (ZDDP). Molybdate esters are unable to form $\mathrm{MoS}_{2}$ without other additive interactions due to a lack of sulfur in their structure. One such commercial example of these additives is the mixture of amide and ester structures presented in (Fig. 1b). In addition to these structures, molybdate salts can also be stabilized by long chain amines and other amphiphiles. De Barros Bouchet et al. [19] have proposed that this additive decomposes via sulfur exchange of the molybdate structure with ZDDP to form oxythiomolybdate and tetrathiomolybdate intermediates. Tetrathiomolybdates have previously been shown to be effective sources of $\mathrm{MoS}_{2}$ for friction reduction in aqueous solutions $[29,30]$. The friction-reducing properties of this additive have been shown to be improved through the addition of amine dispersants to model oil systems [19]. Oumahi et al. [31] showed that the molybdate ester additive in conjunction with ZDDP forms $\mathrm{MoS}_{2}$ tribofilms with $\mathrm{MoS}_{3}$ as a decomposition intermediate. In milder contact condition tests with higher friction, more $\mathrm{MoS}_{3}$ was observed. As contact conditions were made harsher, more crystalline $\mathrm{MoS}_{2}$ was found by Raman spectroscopy. Unlike for the MoDTC dimer, Raman spectroscopic analysis of the molybdate ester and MoDTC trimer has not shown the presence of iron molybdate peaks.

It is widely accepted that all these additive structures are capable of forming $\mathrm{MoS}_{2}$ in a contact and of providing improved friction performance. However, it is not clear if these additives form $\mathrm{MoS}_{2}$ through the same mechanism, or whether the additive chemistry affects the nature of the $\mathrm{MoS}_{2}$ tribofilms formed from them. The additives have been shown to have different levels of friction performance under identical tribological conditions, depending on the contact conditions and surface chemistry. Therefore, the choice of additive structure has an effect on friction for a given system, possibly by reacting to produce $\mathrm{MoS}_{2}$ films with different properties. It is of interest to determine if the choice of molybdenum additive chemistry changes the nature of the films derived from those additives. Is the film derived from molybdenum friction modifiers common to all additives or does the choice of friction modifier structure affect the coverage, thickness, and chemistry of the films? Answering this question would be helpful to determine if intermediates proposed for additive decomposition are common to all additives, such that they may all decompose by similar mechanisms. In addition, it is desirable to be able to relate the properties of an $\mathrm{MoS}_{2}$ tribofilm to its friction performance such that a model for an ideal tribofilm can be constructed. Therefore, comparisons of the properties of films derived from different additive structures can be helpful in future molecular design.

In this study, the differences, both physical and chemical, between the molybdenum disulfide structures formed from each of the three additives, MoDTC dimer, MoDTC trimer, and molybdate ester under identical tribological conditions were assessed. Understanding the chemistry of $\mathrm{MoS}_{2}$ formation of these additives can aid mechanistic understanding and inform future molecular design.

\section{Materials and Methods}

\subsection{Lubricants and Tribological Conditions}

The additives used in this work were a mixture of laboratory synthesized and industrial molybdenum additives. The MoDTC dimer was a laboratory synthesized MoDTC dimer with the level of sulfurization presented in Fig. 1a. As the level of oxidation of this additive can vary in industrial formulations, it is important to control oxidation with a synthesized additive to keep surface-binding and decomposition behavior as consistent as possible. The MoDTC dimer had 2-ethylhexyl R groups. The MoDTC trimer was an industrial additive with a $\mathrm{C} 8-\mathrm{C} 18$ length alkyl $\mathrm{R}$ groups. The molybdenum-sulfur core can exist in alternate forms, the form presented in Fig. 1c predominates to the best of current structural knowledge. The molybdate ester is an industrial mixture of molybdate esters and amides with alkyl chain lengths of $\mathrm{C} 8-\mathrm{C} 18$.

The tribological properties of these additives were studied in both monoblend and fully formulated oil (FFO) lubricant formulations. The monoblend oils contained the additives at $500 \mathrm{ppm}[\mathrm{Mo}]$ in a Group IV polyalphaolefin (PAO) SAE $0 \mathrm{~W}$ grade base stock. This base stock for the monoblends has a kinematic viscosity of $18.3 \mathrm{cSt}$ at $40^{\circ} \mathrm{C}$ and $4.2 \mathrm{cSt}$ at $100{ }^{\circ} \mathrm{C}$. The fully formulated systems contained a full package of additives, including molybdenum additives at $800 \mathrm{ppm}[\mathrm{Mo}]$ and a mixture of primary and secondary C3-C10 ZDDPs at $750 \mathrm{ppm}[\mathrm{P}]$ in a SAE $0 \mathrm{~W}-08$ grade base stock. The fully formulated oils had a kinematic viscosity of $24.9 \mathrm{cSt}$ at $40{ }^{\circ} \mathrm{C}$ and $5.3 \mathrm{cSt}$ at $100{ }^{\circ} \mathrm{C}$. A PAO base oil was used as a control for the monoblend systems with a kinematic viscosity of $18.2 \mathrm{cSt}$ at $40^{\circ} \mathrm{C}$ and $4.2 \mathrm{cSt}$ at $100{ }^{\circ} \mathrm{C}$. A fully formulated oil without molybdenum was used with the same ZDDP concentration described previously and 
a kinematic viscosity of $24.6 \mathrm{cSt}$ at $40{ }^{\circ} \mathrm{C}$ and $5.3 \mathrm{cSt}$ at $100{ }^{\circ} \mathrm{C}$. All oil systems were provided by Infineum UK.

Tribological testing was performed with AISI 52100 steel pins and plates using a Cameron-Plint TE77 reciprocating pin-on-plate tribometer. The plates had dimensions of $15 \mathrm{~mm} \times 15 \mathrm{~mm} \times 3 \mathrm{~mm}$, the pins were $6 \mathrm{~mm}$ in diameter with a curved head. The radius of curvature of the pin's head was $40 \mathrm{~mm}$. The tribological contact conditions were selected to produce chemically representative tribofilms for study. These conditions are not intended to simulate any particular engine contact but provide a suitable boundarylubricated contact for the facile formation of $\mathrm{MoS}_{2}$ tribofilms. Tribofilm formation took place under the conditions outlined in Table 1.

Table 1 Tribological contact conditions for formation of $\mathrm{MoS}_{2}$ tribofilms

\begin{tabular}{ll}
\hline Condition & Value \\
\hline Load & $100 \mathrm{~N}$ \\
Plate surface roughness $\left(\mathrm{R}_{\mathrm{a}}\right)$ & $40-60 \mathrm{~nm}$ \\
Frequency & $5 \mathrm{~Hz}$ \\
Sliding speed & $0-0.11 \mathrm{~ms}^{-1}$ (Recip- \\
& rocating range) \\
& $0.07 \mathrm{~ms}^{-1}$ (Mean) \\
Maximum nominal hertzian contact pres- & $342 \mathrm{MPa}$ \\
$\quad$ sure & $228 \mathrm{MPa}$ \\
Mean nominal hertzian contact pressure & $2 \mathrm{~h}$ \\
Test duration & $100{ }^{\circ} \mathrm{C}$ \\
Lubricant bath temperature & $40 \mathrm{~mm}$ \\
Pin radius of curvature & $504 \mathrm{~m}$ \\
Sliding distance & $7 \mathrm{~mm}$ \\
Stroke length & 0.05 \\
Maximum lambda ratio & \\
\hline
\end{tabular}

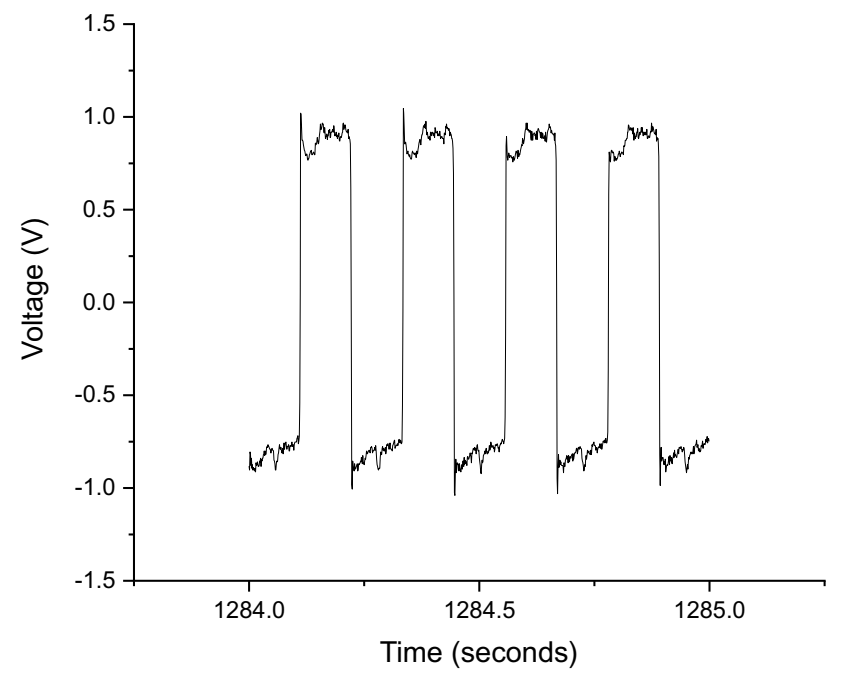

Fig. 2 Voltage square wave response of the tribometer load cell in reciprocating contact
The reciprocating friction force is measured by a load cell, which outputs a square voltage wave (Fig. 2). Every $30 \mathrm{~s}$, the square wave voltage is recorded for $1 \mathrm{~s}$ with 1000 data points. The root-mean-square value of the modulus of the wave amplitude is then compared to a load versus cell voltage calibration curve for the load cell. Division of this value by the normal load allows the coefficient of friction for the measured time to be determined. This procedure provides a coefficient of friction value point every $30 \mathrm{~s}$, to produce friction traces against time. To determine the mean final friction coefficients, the mean friction coefficient value of the final ten minutes of the friction test was taken. Three repeats of each oil system were performed to ensure the repeatability of the observed behavior of the oils. Standard deviation error of the final $10 \mathrm{~min}$ friction coefficients values of the repeats was also calculated to show the variance in final friction coefficient values observed in the test repeats.

The specimens were ultrasonically cleaned in heptane for $10 \mathrm{~min}$ before and after tribological testing to remove supernatant oil and wear debris.

\subsection{Surface Analysis}

The chemical compositions of the tribofilms were studied using Raman spectroscopy and X-ray photoelectron spectroscopy (XPS). Raman spectroscopic analysis of the plate wear scars was performed with a Renishaw inVia spectrometer with a $488 \mathrm{~nm}$ laser at $1.6 \mathrm{~mW}$ laser power to prevent laser-induced oxidation of the tribofilm surface to $\mathrm{MoO}_{3}$, as observed by Khaemba et al. [6, 32]. Mapping of the tribofilm surface was performed in a lattice of point spectra across the central $500 \mu \mathrm{m}$ of the wear scar, along the sliding direction. To construct the maps, point spectra were taken at $50 \mu \mathrm{m}$ intervals in both the $\mathrm{x}$ - and y-directions for a total of 286 spectra per map. The Raman maps cover the entire width of the wear scars and extend $50 \mu \mathrm{m}$ beyond the edges of the wear scar in the y-direction. Maps are taken halfway along the $7 \mathrm{~mm}$ long wear scars from an origin point defined as the top-left corner of the wear scar. The mapping area for the wear scars is given in Fig. 3. The spectral acquisition conditions are given in Table 2.

Maps were constructed of the $\mathrm{MoS}_{2} \mathrm{~A}_{1 \mathrm{~g}}, 408 \mathrm{~cm}^{-1}$ peak intensity and the intensity scale was set to that of the highest scattering intensity peaks, found for the mapping of the

Table 2 Raman acquisition parameters used in tribofilm analysis

\begin{tabular}{ll}
\hline Parameter & Value \\
\hline Laser wavelength & $488 \mathrm{~nm}$ \\
Laser power & $1.6 \mathrm{~mW}$ \\
Accumulations & 1 \\
Exposure time & $20 \mathrm{~s}$ \\
Frequency window & $100-1600 \mathrm{~cm}^{-1}$ \\
\hline
\end{tabular}




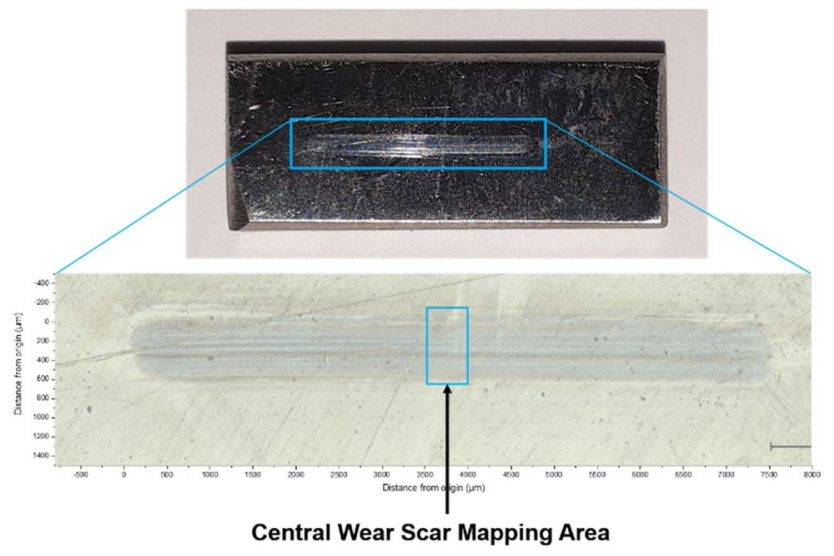

Fig.3 Raman mapping area in center of wear scar

MoDTC trimer in both the fully formulated systems and in the monoblend systems. In addition to the out-of-plane $\mathrm{A}_{1 \mathrm{~g}}$ peak, $\mathrm{MoS}_{2}$ has another distinct in-plane vibration at $380 \mathrm{~cm}^{-1}$ of $\mathrm{E}_{2 \mathrm{~g}}$ symmetry. Raman maps were constructed of the $A_{1 g}$ peak as this is the more intense of the two, making identification of the presence of $\mathrm{MoS}_{2}$ simpler.

XPS was performed at the University of Leeds versatile X-ray source facility (VXSF) using a UHV-XPS system with a monochromatic Specs Focus 500 XR50 Al Ko $1486.6 \mathrm{eV}$ $\mathrm{X}$-ray source with a $0.85 \mathrm{eV}$ line width and a hemispherical $150 \mathrm{~mm}$ Phoibos 150 1D DLD analyzer. Survey spectra were taken at a $50 \mathrm{eV}$ pass energy, and high-resolution spectra were studied at $30 \mathrm{eV}$ pass energy. The XPS-analyzed area was an ellipse measuring $3.5 \mathrm{~mm} \times 0.2 \mathrm{~mm}$ across the width of the wear scar. Spectra were calibrated to the C1s peak at $284.8 \mathrm{eV}$ and fitted with a Gaussian-Lorentzian peak model on a Shirley background. A Shirley background was chosen over a linear background to ensure that appropriate peak areas were included in regions where spectral intensity decreases with binding energy. A Tougaard background was also found not to be appropriate due to the number of expected peak overlaps in the Mo $3 \mathrm{~d}$ and $\mathrm{S} 2 \mathrm{p}$ regions. For a Tougaard background to be effective, the binding energy range needed to correctly calculate the background of the S2p signals would infringe upon the Si 2 s $(151 \mathrm{eV})$ peak from the silicate additives in the fully formulated oils. The result of including the Silicon peak in the background calculation would lead to an inaccurate Tougaard background for the system [33]. A Shirley background was found to be the most appropriate, as it is able to compute a representative background without including contaminating effects from other element peaks than those of interest [33].

The areas of the Mo $3 \mathrm{~d}$ doublets were fitted with an intensity ratio of 3:2. Similarly, the areas of the $S 2 p$ doublets were area constrained to a 2:1 intensity ratio. These area constraints were imposed to account for the degeneracy of the orbitals involved in spin-orbit coupling for the Mo 3d and S 2p doublets, respectively [33-35]. The \% at concentration of these doublets was calculated using the relative sensitivity factor for both peaks in the doublet, rather than using the relative sensitivity factor for a single doublet peak. This treatment applied to both the Mo 3d and S 2p doublets, respectively. This method was chosen to improve signal-tonoise ratio when both doublet peaks are available, especially in those molybdate ester tests where less surface sulfur coverage was observed. The splitting for the peak doublets was fixed at 3.13 and $1.18 \mathrm{eV}$ for the Mo $3 \mathrm{~d}$ and $\mathrm{S} 2 \mathrm{p}$ doublets, respectively. The full-width-half maxima (FWHM) of Mo $3 \mathrm{~d}$ peaks were constrained to be less than $2 \mathrm{eV}$, and the FWHM of sulfur peaks were constrained to be less than $1.4 \mathrm{eV}$. Peak positions for Mo 3d spectra were constrained to be $\pm 0.3 \mathrm{eV}$ as a maximum from their literature reported values in model compounds [34, 36-38]. Sulfur peak positions were constrained within the range $\pm 0.2 \mathrm{eV}$ from their literature reported peak positions [35-38].

\subsection{Nanostructure of the Tribofilms Derived from Monoblend Oils}

Cross sections of the tribofilm were cut with a FEI Helios G4 CX gallium focused ion beam (FIB) to prepare $5 \mu \mathrm{m}$ wide slices for transmission electron microscopy. To prevent sputtering-induced amorphization of the tribofilms, the surfaces were protected with an Iridium layer prior to FIB milling. Areas of highest $\mathrm{MoS}_{2}$ scattering intensity within the wear scar from the Raman maps were selected to be cut for FIB-TEM analysis.

Transmission electron microscopy (TEM) was performed upon the FIB cross sections to view the tribofilms as a function of depth. The chemical composition of the film was studied with energy-dispersive X-ray spectroscopy (EDX). A Thermofisher Titan Themis ${ }^{3}$ was operated at $300 \mathrm{kV}$ to acquire the TEM data. The bright-field TEM images were collected on a Gatan OneView 16 Megapixel CMOS digital camera. The elemental maps were collected with a STEM probe current of 40pA using Super-X EDX system with windowless 4-detector design and 0.7 srad solid angle.

\section{Results}

\subsection{Friction Tests}

Tribological tests of the monoblend and fully formulated oil systems were performed using the contact conditions outlined in Table 1. Representative friction-time traces are presented below in Fig. 4. The mean coefficients of friction in the final 10 min of a test are presented in Fig. 5. Each of the systems containing both molybdenum and sulfur provided lower friction coefficients than the control oils (base oil and 


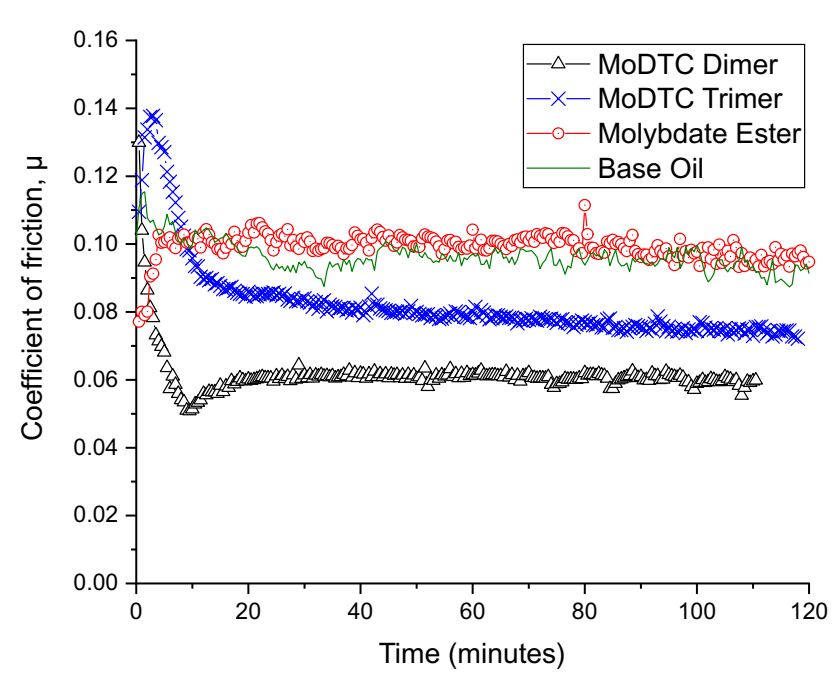

(a) Monoblend oil systems

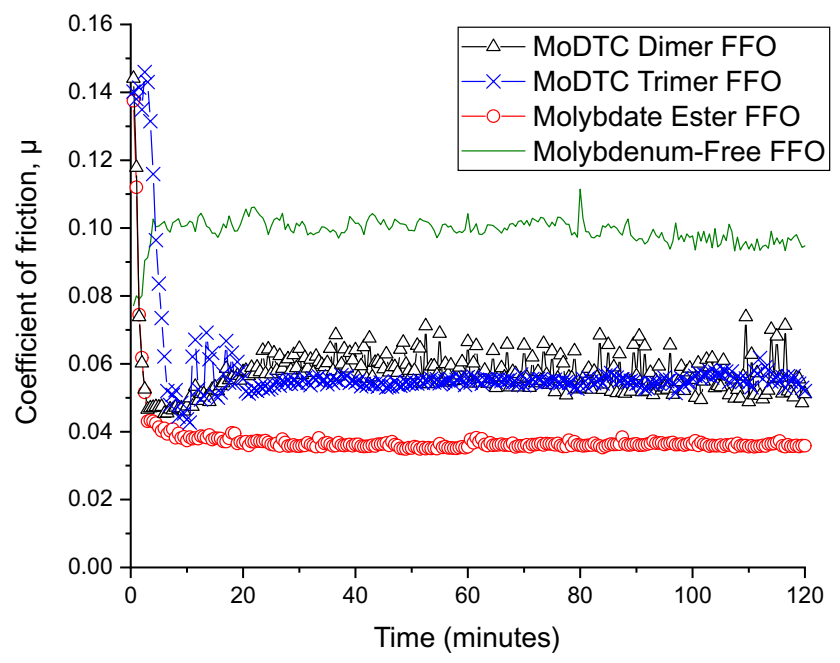

(b) Fully formulated oil systems

Fig. 4 Friction profiles of the molybdenum-sulfur additives in monoblend (a) and fully formulated oils systems (b)

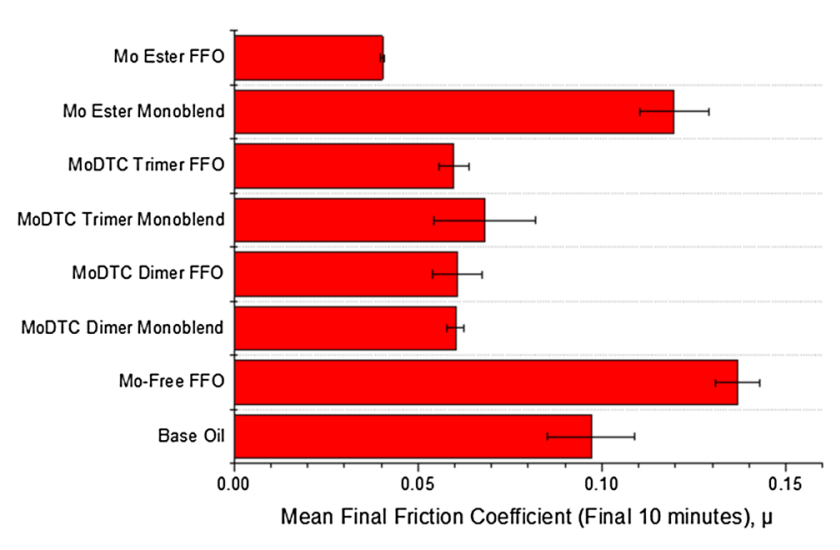

Fig. 5 Mean final friction coefficients of the oil systems studied

molybdenum-free fully formulated oil for the monoblends and fully formulated systems, respectively), as expected. The molybdate ester monoblend and molybdenum-free FFO systems showed no friction reduction relative to base oil.

It can be seen from the friction traces in Fig. 4a that the monoblends of the MoDTC dimer and MoDTC trimer show comparable friction coefficients of $\mu \approx 0.06-0.08$. The MoDTC trimer has a longer induction period to reach its steady-state final friction coefficient than the MoDTC dimer. The molybdate ester monoblend displays no drop in friction. This is due to the lack of sulfur in the formulation preventing the formation of $\mathrm{MoS}_{2}$. However, in the case of a fully formulated oil system in Fig. 4b, there is a significant reduction in friction consistent with $\mathrm{MoS}_{2}$ formation. In these fully formulated systems, ZDDP is available to the molybdate ester as a plentiful source of sulfur, both in solution and at the contacting surfaces. This shows how critical the interactions of the molybdate ester with the rest of an additive package are to its performance. Although there is no sulfur in the additive structure of the molybdate ester, it is still capable of providing low friction effectively via its additive interactions.

The CoF values of the oil systems are presented in Fig. 5 . The mean coefficient of friction for the final $10 \mathrm{~min}$ of the $2 \mathrm{~h}$ tribological tests is presented for each oil system. The fully formulated systems in general show improved performance relative to the monoblends. The molybdate ester fully formulated system consistently displays a lower $\mathrm{CoF}$ than the other additive systems under the tribological conditions studied.

\subsection{Raman Mapping}

To determine the distribution and overall level of $\mathrm{MoS}_{2}$ coverage on the surfaces, Raman spectroscopic mapping was performed in a central region of the wear scar. The bounds of the wear scar are given by solid pink lines superimposed upon the map data.

The fully formulated MoDTC dimer and MoDTC trimer oils (Fig. 6a, b) displayed patchy distributions of the $408 \mathrm{~cm}^{-1} \mathrm{~A}_{1 \mathrm{~g}}$ peak intensity, with much higher scattering intensities than those found for the monoblend systems (Fig. 7). In these fully formulated systems, the areas of highest intensity were found along the center line of the wear scar width, closer to the center of the Hertzian contact area where tribological conditions are likely to be their most harsh. The molybdate ester (Fig. 6c) showed little Raman scattering intensity within the wear scar. To determine if this was due to a lack of $\mathrm{MoS}_{2}$ within the wear scar, or simply 
(a)

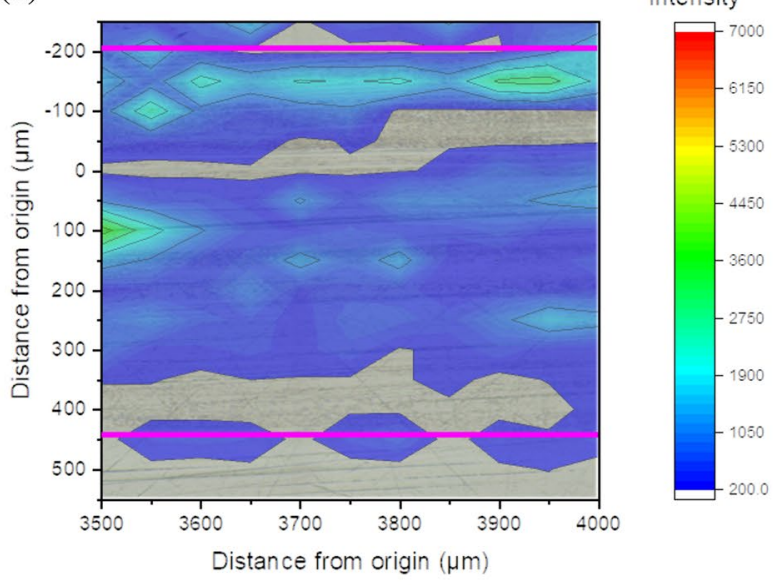

(b)

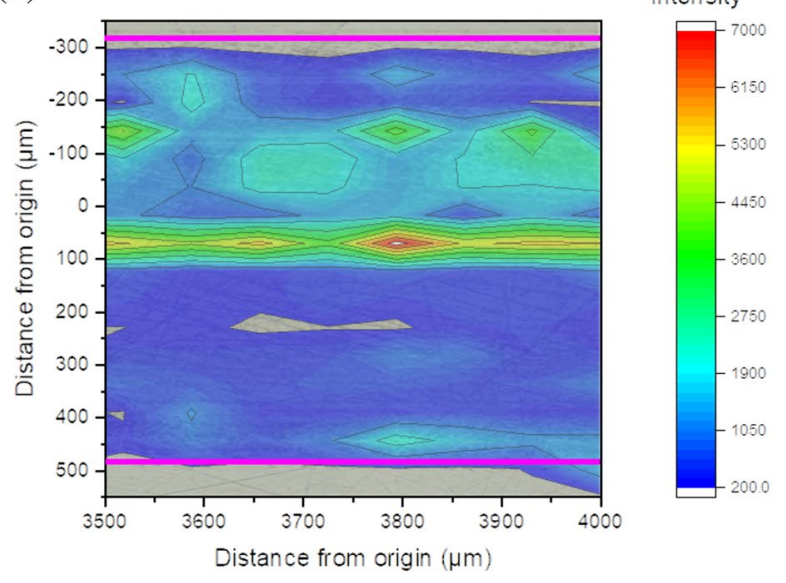

(c)

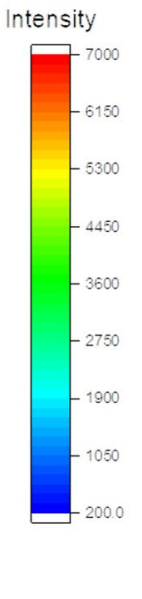

Fig. 6 Raman spatial distribution maps of $408 \mathrm{~cm}^{-1}$ intensity peaks for MoDTC dimer (a), MoDTC trimer (b), and molybdate ester (c) fully formulated oils

due to low intensity scattering relative to the scattering at the wear scar edges, a map was constructed in Fig. 8 of the positions in which $\mathrm{MoS}_{2}$ was found for the additives, by visual inspection of the individual mapping spectra, independent of the scattering intensity. The presence of $\mathrm{MoS}_{2}$ on the surface was determined by the presence of visually identifiable $\mathrm{A}_{1 \mathrm{~g}}$ and $\mathrm{E}_{2 \mathrm{~g}}$ peaks of $\mathrm{MoS}_{2}$ in the Raman spectra. The $\mathrm{MoS}_{2}$ surface coverage was calculated for the areas mapped as the percentage of nodes where $\mathrm{MoS}_{2}$ was confirmed to be present.

It can be seen from the $\mathrm{MoS}_{2}$ distribution maps in Fig. 8 that there is less area coverage of $\mathrm{MoS}_{2}$ in the wear scar of the molybdate ester system than the dimer and trimer systems. The MoDTC dimer and MoDTC trimer showed an even surface coverage across the wear scar, whereas the molybdate ester had only a very patchy distribution in the wear scar. This contrasts with the results of Oumahi et al. [31] who found that surface coverage of $\mathrm{MoS}_{2}$ derived from the molybdate ester of greater than $60 \%$ were required to achieve a friction coefficient value of $\mu=0.04$.

The mean spectra of the Raman mapping areas shown in Figs. 6 and 7 are shown below in Fig. 9. In the mean spectra of the oil systems, there are contributions from $\mathrm{MoS}_{2}$ and iron oxides from the steel surface, no peaks for either molybdenum oxides of iron molybdates were found in the mapping spectra. In addition to the $\mathrm{A}_{1 \mathrm{~g}}$ and $\mathrm{E}_{2 \mathrm{~g}}$ peaks of $\mathrm{MoS}_{2}$, the tribofilms displayed additional peaks at 456 and $555 \mathrm{~cm}^{-1}$ that can be identified as the vibration of molybdenum with the apical sulfur in $\mathrm{Mo}_{3} \mathrm{~S}_{13}$ core units and $\mathrm{S}-\mathrm{S}$ bridging sulfur stretches, respectively. These structural features are that found in the structure of the MoDTC trimer and amorphous molybdenum sulfides [39-41]. These spectral features were found in the spectra for all of the additive films where $\mathrm{MoS}_{2}$ was observed. This suggests that this feature is a common part of the decomposition products of all the additives.

To determine if any of the oil systems showed had a greater contribution from amorphous $\mathrm{MoS}_{3}$ peaks than 

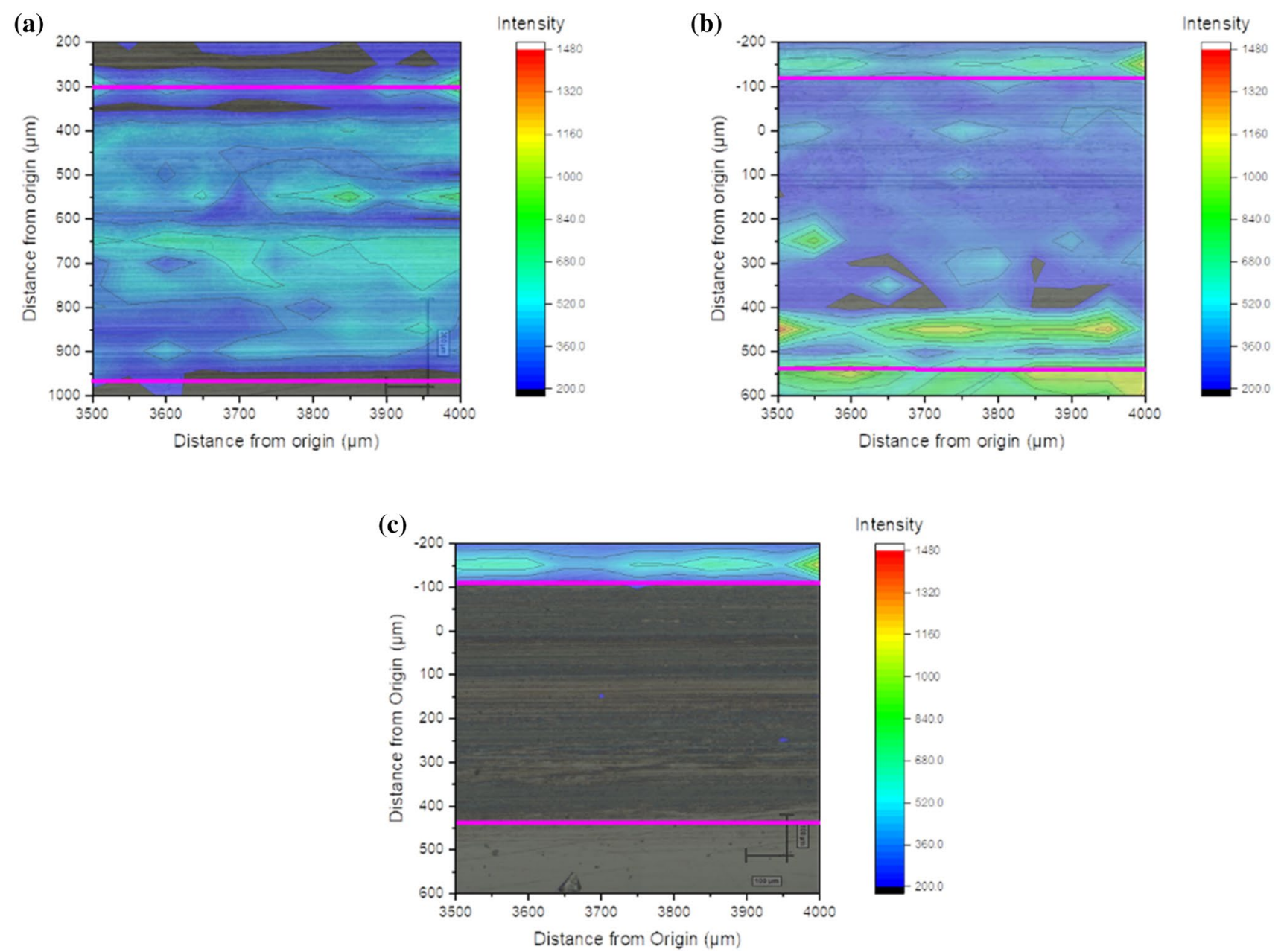

Fig. 7 Raman spatial distribution maps of $408 \mathrm{~cm}^{-1}$ intensity peaks for MoDTC dimer (a), MoDTC trimer (b), and molybdate ester (c) monoblends (note change in scattering intensity scale from Fig. 6)

Fig. 8 (Above) Distribution of $\mathrm{MoS}_{2}$ for fully formulated oil systems: MoDTC dimer (a), MoDTC trimer, (b) and molybdate ester (c). Red shows the presence of $\mathrm{MoS}_{2} \mathrm{~A}_{1 \mathrm{~g}}$ and $\mathrm{E}_{2 \mathrm{~g}}$ peaks and blue their absence. (Below) $\mathrm{MoS}_{2}$ surface coverage for the oil systems studied, determined by Raman (Color figure online)

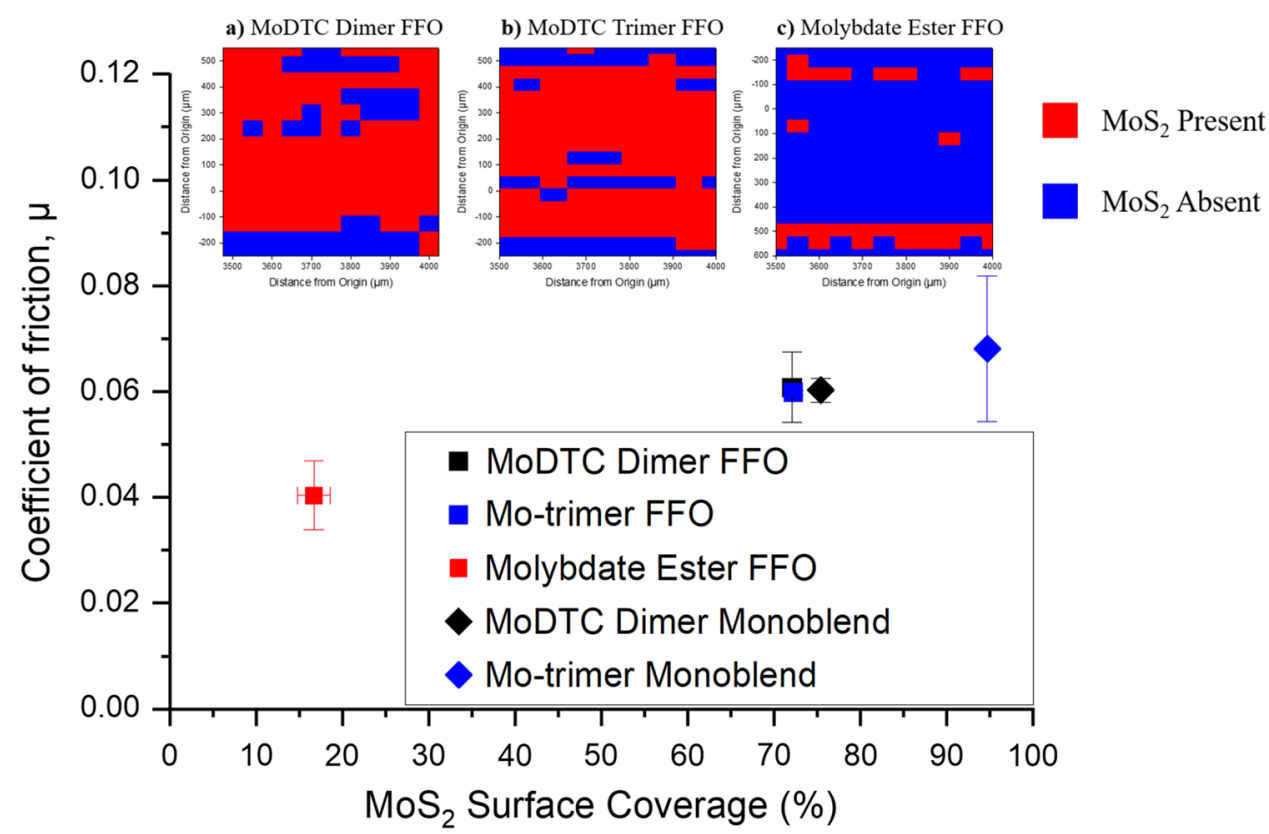



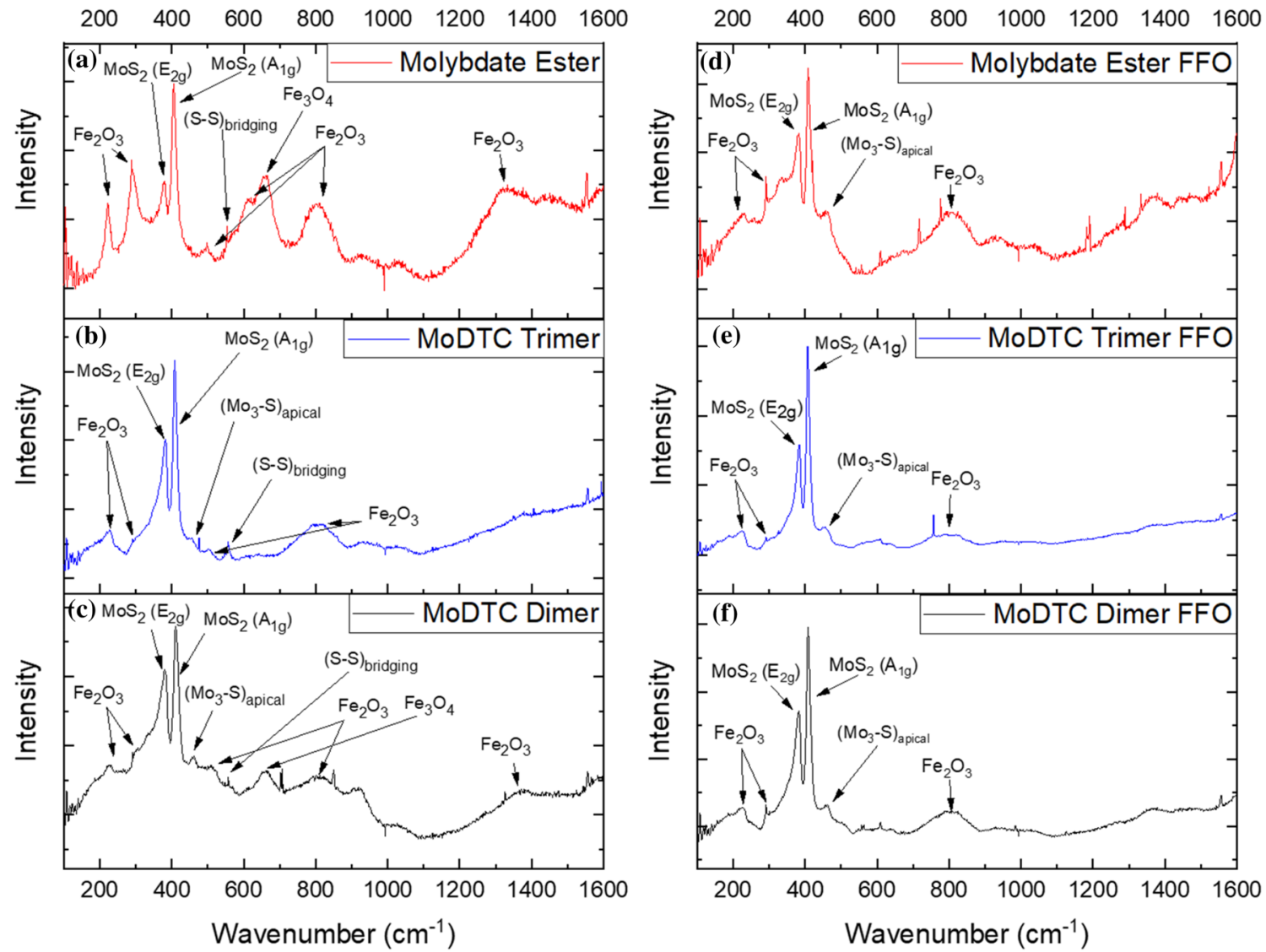

Fig. 9 Mean Raman spectra of the wear scar mapping areas for each oil system

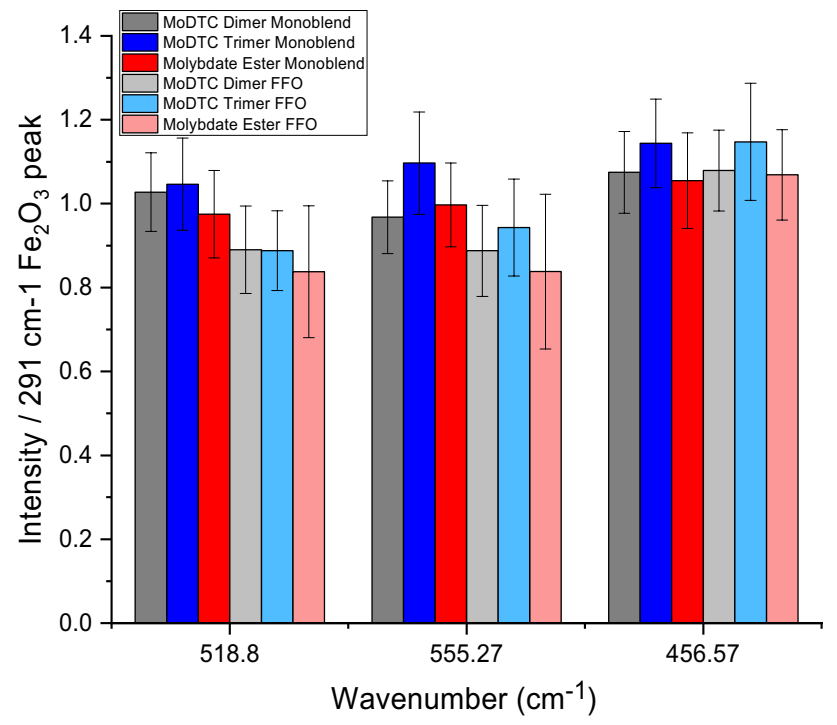

Fig. 10 Peak intensity ratios between $\mathrm{MoS}_{3}$ peaks and $\mathrm{Fe}_{2} \mathrm{O}_{3}$ $291 \mathrm{~cm}^{-1}$ peak derived from the mapping spectra where $\mathrm{MoS}_{2} \mathrm{~A}_{1 \mathrm{~g}}$ peak intensity was greater than 200 counts the others, the peak ratios between the $\mathrm{Fe}_{2} \mathrm{O}_{3} 291 \mathrm{~cm}^{-1}$ vibrational mode and the three identifiable $\mathrm{MoS}_{3}$ peaks at $456 \mathrm{~cm}^{-1}\left(\mathrm{Mo}_{3}-\mathrm{S}_{\text {apical }}\right), 518 \mathrm{~cm}^{-1}\left(\mathrm{~S}-\mathrm{S}_{\text {terminal }}\right)$, and $555 \mathrm{~cm}^{-1}$ $(\mathrm{S}-\mathrm{S})_{\text {bridging }}$ were calculated for the mapping spectra which contained an $\mathrm{MoS}_{2} \mathrm{~A}_{1 \mathrm{~g}}$ scattering intensity of 200 counts or greater, as in Figs. 6 and 7. This $291 \mathrm{~cm}^{-1} \mathrm{Fe}_{2} \mathrm{O}_{3}$ peak was chosen as it is common in the mapping spectra and has a sharply defined maximum unlike the 220 and $808 \mathrm{~cm}^{-1}$ peaks and like the $\mathrm{MoS}_{3}$ peak region, are affected by the $\mathrm{MoS}_{2}$ fluorescence signal more closely than the other iron oxide peaks. The peak intensity ratios are presented in Fig. 10. In both the monoblends and the fully formulated systems, a slight increase in the relative $\mathrm{MoS}_{3}$ peak intensity was observed for the MoDTC trimer compared to the other two additives.

\subsection{XPS}

The Raman mapping showed that the tribofilms appeared to be chemically similar, with each additive displaying the same decomposition products on the surface. The data also hinted that there may be more Mo:S species deposition from the MoDTC trimer than the other additive systems through 

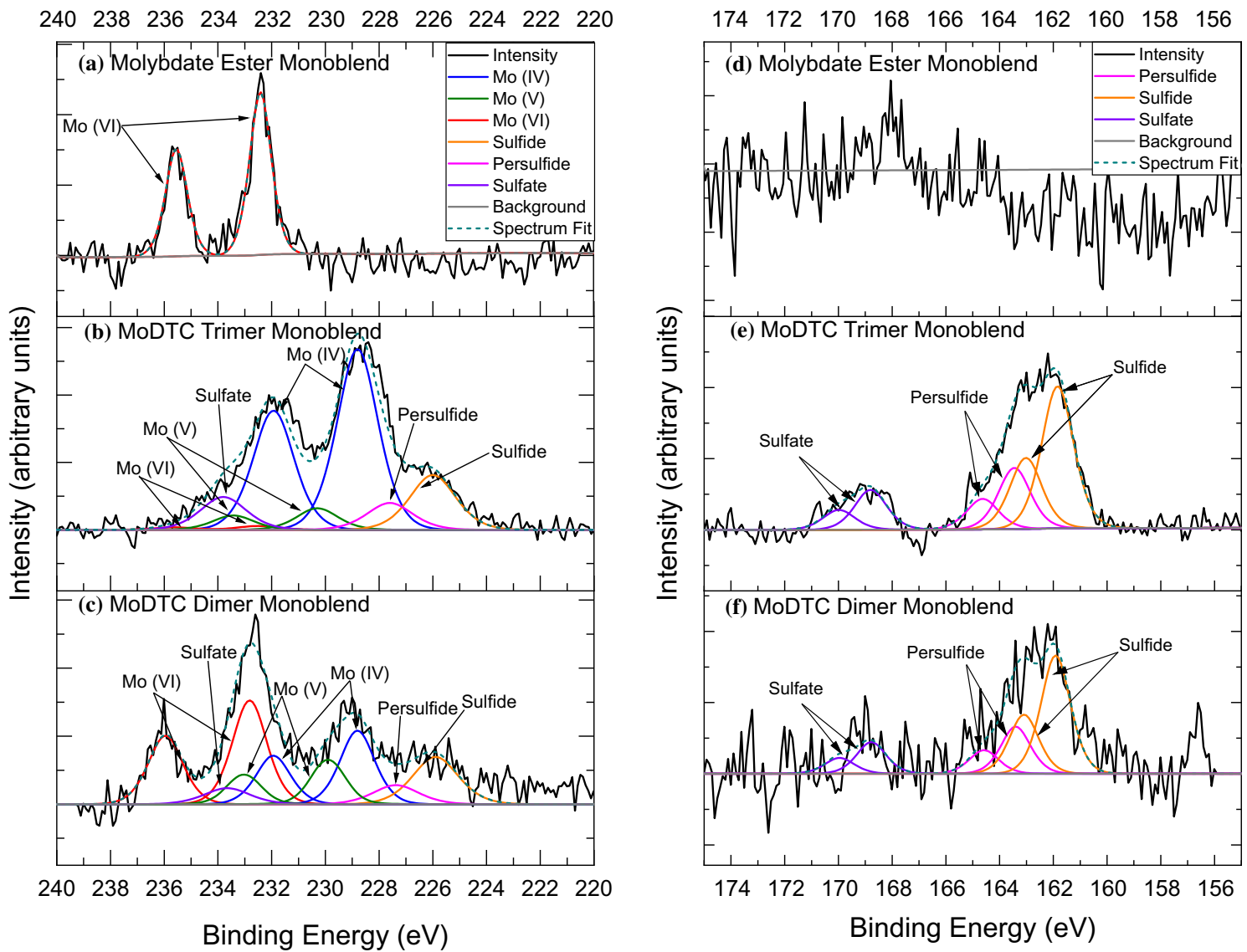

Fig. 11 Mo 3d (left) and S 2p (right) regions of molybdate ester (top) MoDTC trimer (center) and MoDTC dimer (bottom) monoblend oil tribofilms

Table 3 XPS peak information for the monoblend oil tribofilms

\begin{tabular}{|c|c|c|c|c|c|c|c|c|c|}
\hline \multirow[b]{2}{*}{ Peak } & \multicolumn{3}{|c|}{ MoDTC dimer monoblend } & \multicolumn{3}{|c|}{ MoDTC trimer monoblend } & \multicolumn{3}{|c|}{ Molybdate ester monoblend } \\
\hline & Position (eV) & FWHM & $\%$ At conc & Position (eV) & FWHM & $\%$ At conc & Position (eV) & FWHM & $\%$ At conc \\
\hline Mo (VI) $5 / 2$ & 232.81 & 1.53 & 8.19 & 232.5 & 1.80 & 0.32 & 232.41 & 0.96 & 63.48 \\
\hline Mo (VI) $3 / 2$ & 235.94 & 1.53 & 4.71 & 235.63 & 1.80 & 0.19 & 235.55 & 0.96 & 36.52 \\
\hline Mo (V) 5/2 & 229.90 & 1.53 & 3.65 & 230.30 & 1.80 & 1.53 & N/A & & \\
\hline $\operatorname{Mo}(\mathrm{V}) 3 / 2$ & 233.03 & 1.53 & 2.12 & 233.43 & 1.80 & 0.89 & N/A & & \\
\hline Mo (IV) $5 / 2$ & 228.83 & 1.53 & 4.71 & 228.80 & 1.80 & 15.16 & N/A & & \\
\hline Mo (IV) $3 / 2$ & 231.96 & 1.53 & 3.86 & 231.93 & 1.80 & 8.72 & N/A & & \\
\hline S2s sulfide & 225.90 & 2.00 & 43.63 & 226.01 & 2.00 & 38.87 & N/A & & \\
\hline S2s persulfide & 227.34 & 2.00 & 16.56 & 227.6 & 2.00 & 17.76 & N/A & & \\
\hline S2s sulfate & 233.64 & 2.00 & 10.57 & 233.8 & 2.00 & 16.56 & N/A & & \\
\hline S2p sulfide (3/2) & 161.91 & 1.29 & 37.30 & 161.84 & 1.40 & 35.07 & N/A & & \\
\hline S2p sulfide (1/2) & 163.09 & 1.29 & 18.65 & 163.02 & 1.40 & 35.07 & N/A & & \\
\hline S2p persulfide $(3 / 2)$ & 163.40 & 1.29 & 14.86 & 163.40 & 1.40 & 15.12 & N/A & & \\
\hline S2p persulfide $(1 / 2)$ & 164.58 & 1.29 & 7.43 & 164.63 & 1.40 & 7.56 & N/A & & \\
\hline S2p sulfate $(3 / 2)$ & 168.78 & 1.29 & 16.76 & 168.80 & 1.40 & 16.48 & N/A & & \\
\hline S2p sulfate $(1 / 2)$ & 169.96 & 1.29 & 5.00 & 169.98 & 1.40 & 8.24 & N/A & & \\
\hline
\end{tabular}




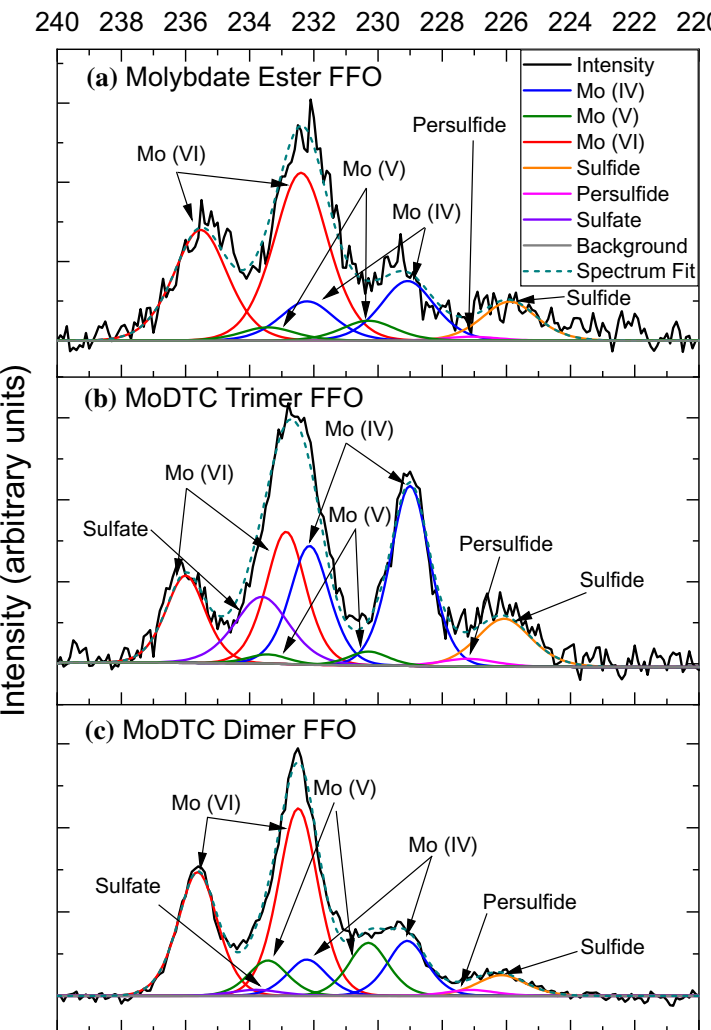

$\begin{array}{lllllllllll}240 & 238 & 236 & 234 & 232 & 230 & 228 & 226 & 224 & 222 & 220\end{array}$ Binding Energy (eV) $\begin{array}{llllllllll}174 & 172 & 170 & 168 & 166 & 164 & 162 & 160 & 158 & 156\end{array}$

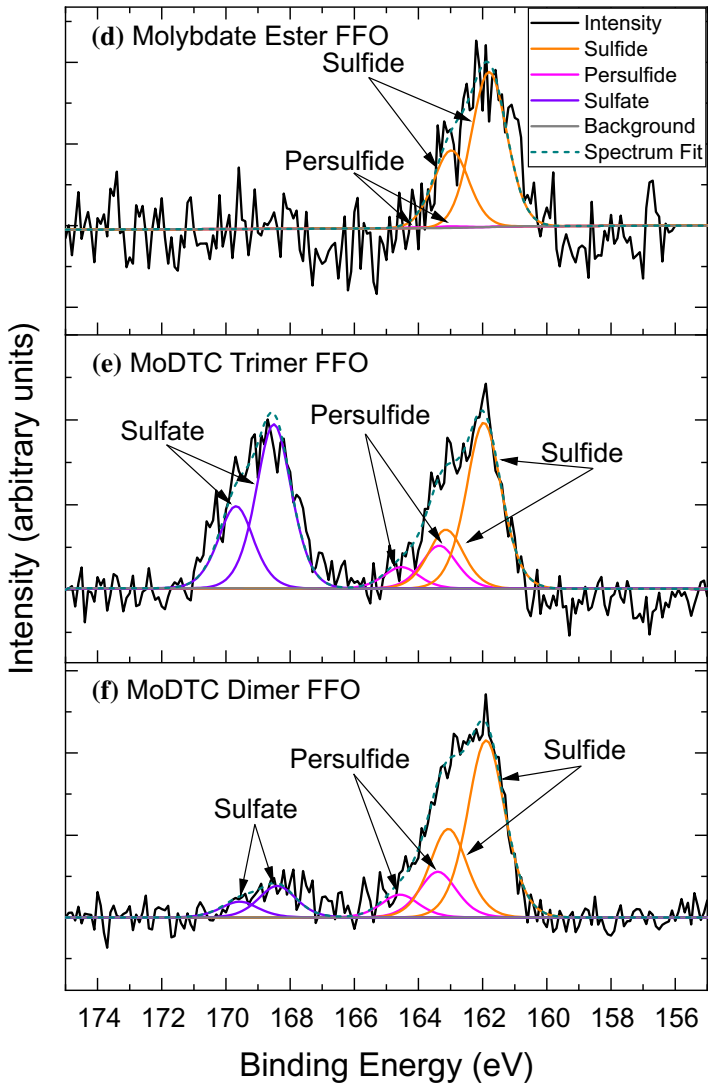

Fig. 12 Mo 3d (left) and S 2p (right) regions of molybdate ester (top) MoDTC trimer (center) and MoDTC dimer (bottom) fully formulated oil tribofilms

Table 4 XPS peak information for the fully formulated oil tribofilms

\begin{tabular}{|c|c|c|c|c|c|c|c|c|c|}
\hline \multirow[b]{2}{*}{ Peak } & \multicolumn{3}{|c|}{ MoDTC dimer FFO } & \multicolumn{3}{|c|}{ MoDTC trimer FFO } & \multicolumn{3}{|c|}{ Molybdate ester FFO } \\
\hline & Position (eV) & FWHM & $\%$ At conc & Position (eV) & FWHM & $\%$ At conc & Position (eV) & FWHM & $\%$ At conc \\
\hline Mo (VI) $5 / 2$ & 232.49 & 1.46 & 22.86 & 232.87 & 1.45 & 7.20 & 232.40 & 1.98 & 21.05 \\
\hline Mo (VI) 3/2 & 235.62 & 1.46 & 13.15 & 236.00 & 1.45 & 4.14 & 235.53 & 1.98 & 12.10 \\
\hline Mo (V) $5 / 2$ & 230.30 & 1.46 & 7.11 & 230.30 & 1.45 & 0.84 & 230.30 & 1.98 & 2.58 \\
\hline Mo (V) 3/2 & 233.43 & 1.46 & 4.13 & 233.43 & 1.45 & 0.49 & 233.43 & 1.98 & 1.50 \\
\hline Mo (IV) $5 / 2$ & 229.09 & 1.46 & 7.78 & 229.00 & 1.45 & 11.60 & 229.11 & 1.98 & 8.89 \\
\hline Mo (IV) 3/2 & 232.22 & 1.46 & 4.48 & 232.13 & 1.45 & 6.68 & 232.24 & 1.98 & 5.12 \\
\hline S2s sulfide & 226.16 & 1.81 & 27.30 & 226.07 & 2.00 & 32.10 & 225.90 & 2.00 & 44.55 \\
\hline S2s persulfide & 227.10 & 1.81 & 7.47 & 227.20 & 2.00 & 4.89 & 227.10 & 2.00 & 4.23 \\
\hline S2s sulfate & 233.80 & 1.81 & 5.72 & 233.62 & 2.00 & 32.07 & N/A & & \\
\hline S2p sulfide (3/2) & 161.89 & 1.37 & 43.96 & 161.96 & 1.29 & 25.67 & 161.80 & 1.21 & 60.61 \\
\hline S2p sulfide $(1 / 2)$ & 163.07 & 1.37 & 21.98 & 163.14 & 1.29 & 9.11 & 162.98 & 1.21 & 30.30 \\
\hline S2p persulfide $(3 / 2)$ & 163.40 & 1.37 & 11.33 & 163.35 & 1.29 & 6.64 & 163.22 & 1.21 & 6.06 \\
\hline S2p persulfide $(1 / 2)$ & 164.58 & 1.37 & 5.67 & 164.53 & 1.29 & 3.32 & 164.40 & 1.21 & 3.03 \\
\hline S2p sulfate (3/2) & 168.40 & 1.37 & 13.14 & 168.51 & 1.29 & 42.57 & N/A & & \\
\hline $\mathrm{S} 2 \mathrm{p}$ sulfate $(1 / 2)$ & 169.58 & 1.37 & 3.92 & 169.69 & 1.29 & 12.79 & N/A & & \\
\hline
\end{tabular}


greater surface coverage. If this is the case, then a greater degree of $\mathrm{MoS}_{2}$ should be expected on the tribofilm surfaces than other species that may not have been detected by Raman. The Mo 3d region can be used to easily distinguish between Mo oxidation states on the tribofilm surface, and the sulfur $S 2 p$ region can provide indication of the presence and chemical state of surface sulfur. XPS was performed on both the monoblend systems (Fig. 11) and the fully formulated oil systems (Fig. 12). Peak quantification information is provided in Tables 3 and 4 respectively.

Each of the three molybdenum additive systems, MoDTC dimer, MoDTC trimer, and molybdate ester, displayed both Mo (IV) and Mo (VI) oxidation state environments for the fully formulated oil systems (Fig. 12) in the Mo 3d binding energy region. A small Mo (V) component was also observed, although this was only significant in MoDTC dimer systems and likely results from the presence of the MoDTC dimer additive structure on the surface. This assignment of oxidation states agrees with those determined by previous XPS studies [11, 19, 34, 36, 42]. The presence of Mo (IV) is due to the presence of $\mathrm{MoS}_{2}$ and amorphous Mo:S species. The molybdate ester monoblend [Fig. 11 (bottom)] showed no Mo (IV) state corresponding to $\mathrm{MoS}_{2}$ and no surface sulfur in the $S 2 p$ region, confirming the lack of $\mathrm{MoS}_{2}$ formation in this system inferred from friction results. However, molybdenum was still found on the steel surface for this system in a Mo (VI) oxidation state, at a binding energy of $232.5 \mathrm{eV}$ typically associated with molybdenum trioxide $\left(\mathrm{MoO}_{3}\right)$. The MoDTC dimer and the MoDTC trimer showed Mo (IV) and (VI) environments in the monoblends (Fig. 11) but did so with different relative ratios of oxidation states.

The MoDTC trimer XPS spectra found a greater proportion of the Mo (IV) state on the surface (monoblend 23.88 at.\%, FFO 18.28 at.\%) relative to the MoDTC dimer (monoblend 8.57 at.\%, FFO 12.26 at.\%) and the molybdate ester (monoblend 0 at.\%, FFO 14.01 at.\%). This suggests a greater relative abundance of Mo (IV) species on the surface, due either to a greater proportion of $\mathrm{MoS}_{2}$ and Mo:S amorphous Mo (IV) species in the film, or a resistance of the formed film to oxidation.

\subsection{FIB-TEM of Monoblend Tribofilms}

To determine if the MoDTC trimer's increased relative abundance of the Mo (IV) oxidation state was the result of a greater proportion of Mo:S species on the surface, it is of interest to determine the structural nature and thickness of the tribofilm on the nanoscale (Fig. 13).

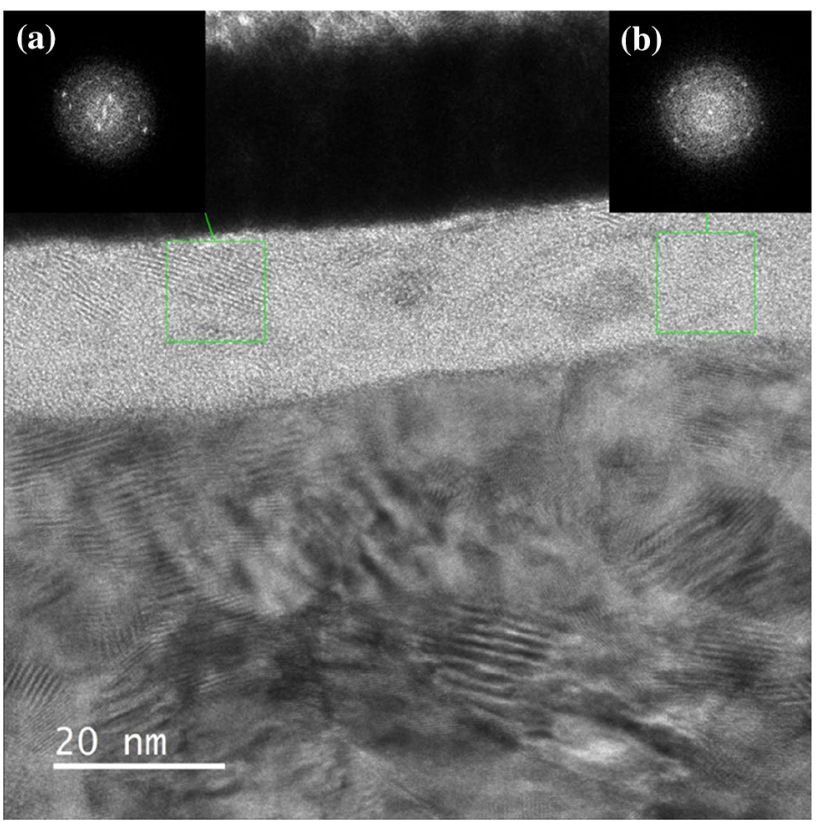

Fig. 13 MoDTC Trimer tribofilm crystallinity regions with inset FFTs of $\mathbf{a}$ crystalline and $\mathbf{b}$ amorphous regions

The MoDTC trimer monoblend (Fig. 14a) tribofilm shows a consistent layer across the FIB section of Mo:S species (as shown by EDX). The film is composed of a mixture of amorphous and crystalline domains highlighted in Fig. 13. Amorphous regions of Mo:S have been proposed as intermediates in $\mathrm{MoS}_{2}$ formation by Khaemba et al. and can be seen in the tribofilms of Rai et al. [15, 43]. The $\mathrm{MoS}_{2}$ crystalline domains are oriented in the sliding direction at the very surface but the subsurface crystalline regions have random orientations. The film had a consistent distribution of iron particles within it (Fig. 14c). In contrast to the structure of the MoDTC trimer film, the MoDTC dimer tribofilm did not show a consistent layer of Mo:S species across the FIB section and these elements were only found in increased concentration in small patches atop iron oxide particles (Fig. 15d). This can be seen in the sulfur EDX image (Fig. 15b) of the dimer, there is a localized increase in sulfur concentration at the top of the iron oxide particle surface. 
(a)

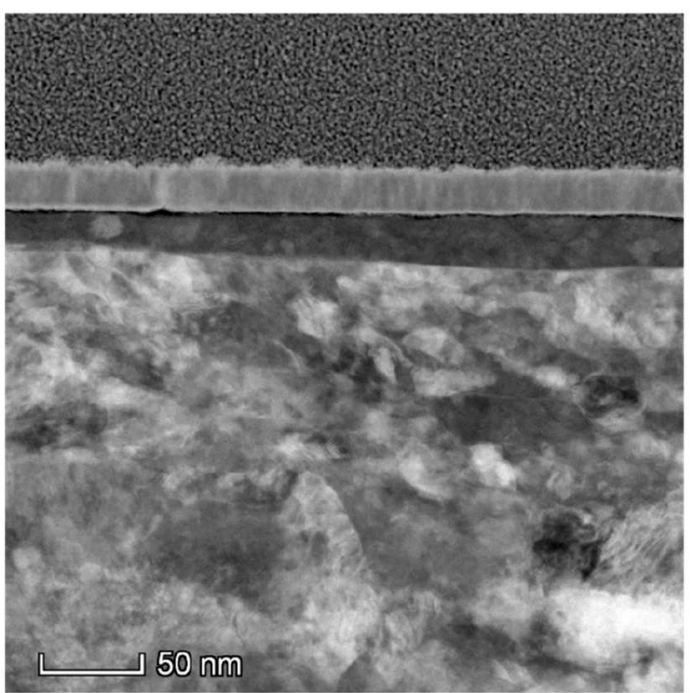

(b)

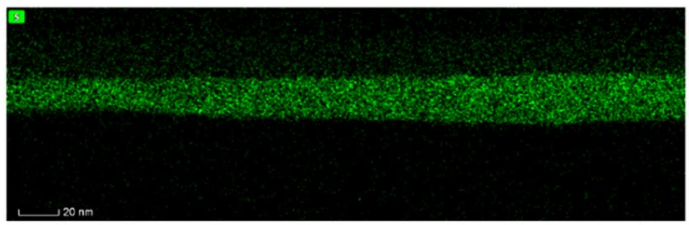

(c)

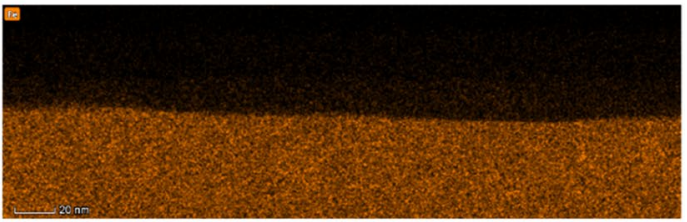

(d)

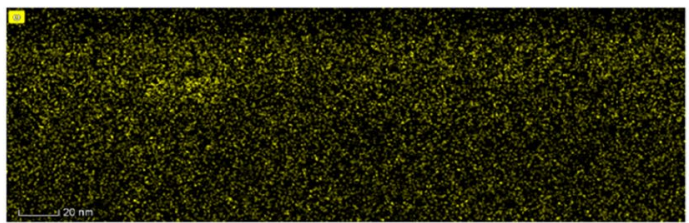

Fig. 14 FIB-TEM cross section of the MoDTC trimer monoblend tribofilm (a), EDX of MoDTC trimer S (b), EDX of Fe (c), and EDX of O (d)

(a)

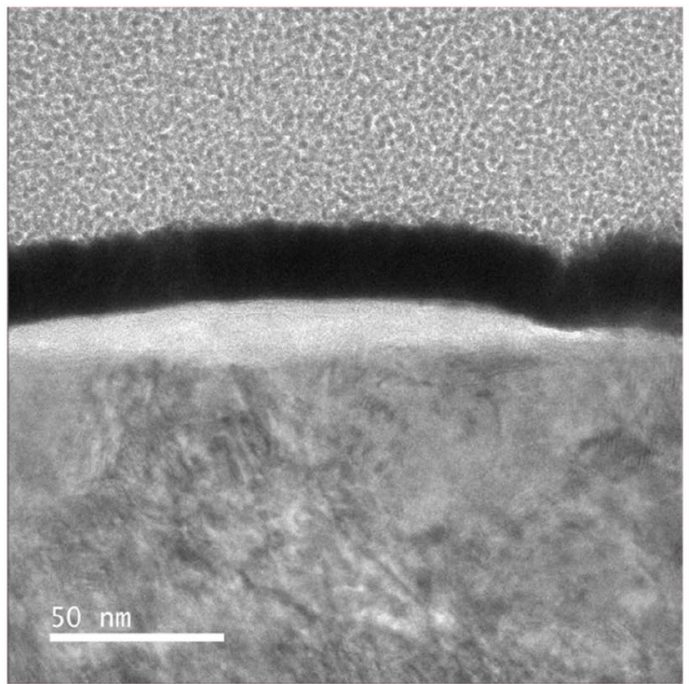

(b)

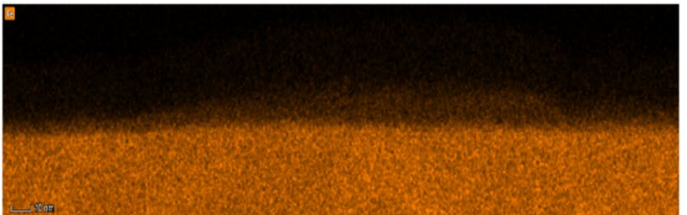

(c)

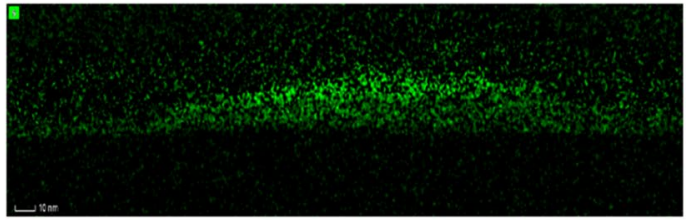

(d)

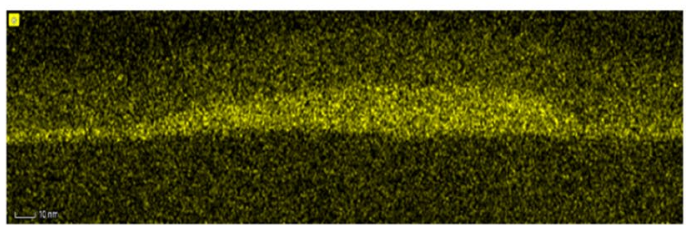

Fig. 15 FIB-TEM cross section of the MoDTC dimer monoblend tribofilm (a), EDX of MoDTC dimer S (b), EDX of Fe (c), and EDX of O (d)

\subsection{Durability of Formed Tribofilms}

The TEM cross sections of the MoDTC dimer and MoDTC trimer monoblends show that the film derived from the MoDTC dimer monoblend is much thinner than that formed from the MoDTC trimer, which displays a consistent $20 \mathrm{~nm}$ thick layer across the entire steel surface.

To determine if this increase in amount of Mo:S species observed in the MoDTC trimer TEM resulted in a more durable tribofilm, a durability test similar to that conducted by Morina and Neville was performed [44]. A tribofilm was created for the MoDTC dimer and MoDTC trimer monoblends under the conditions listed in Table 1 and after thirty minutes the additive-containing oil was removed, the oil bath was cleaned with heptane and then filled with base oil. The components were removed and ultrasonically rinsed in heptane for $10 \mathrm{~min}$ to ensure that no residual additive-containing oil was present before being replaced in the tribometer. Similar tests were performed for the fully formulated systems except in these tests the replacement oil inserted after 30 min was a Mo-free fully formulated oil.

Figure 16 shows that the MoDTC trimer took slightly longer to reach base oil friction levels again upon oil replacement by base oil than did the MoDTC dimer. Both additives had effectively returned to higher friction coefficients 


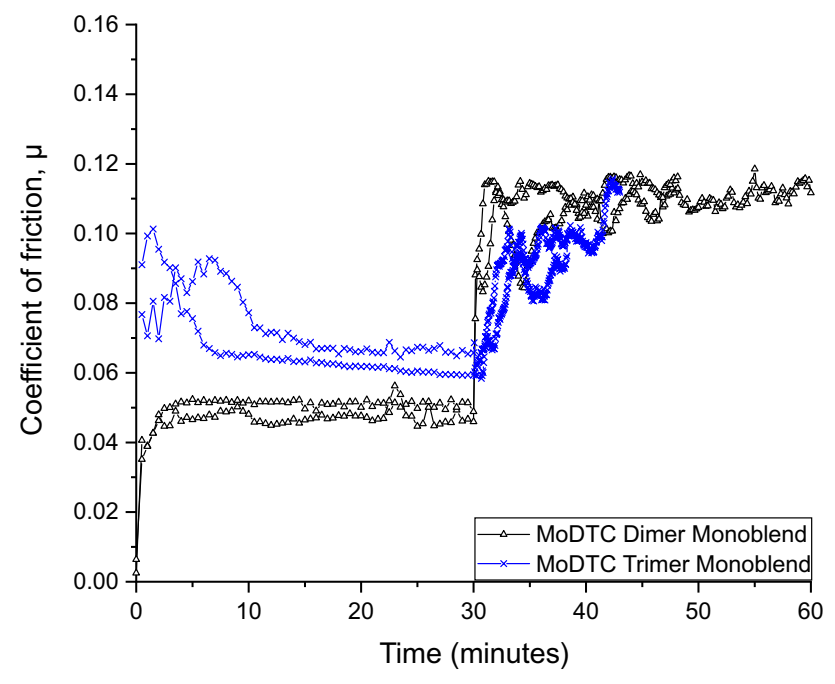

Fig. 16 Durability of the monoblend MoDTC dimer (black) and MoDTC trimer (blue) tribofilms (Color figure online)

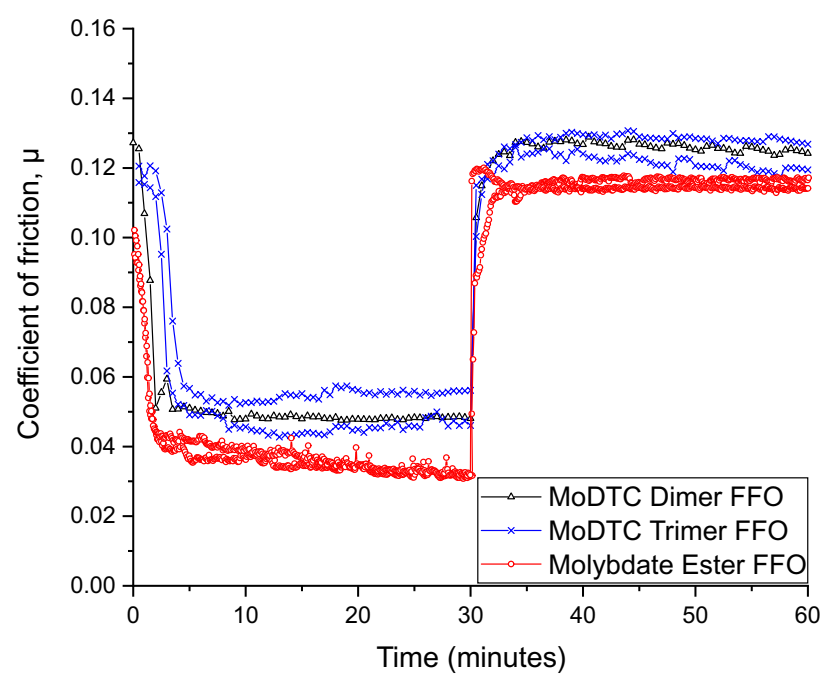

Fig. 17 Durability of the fully formulated MoDTC dimer (black), MoDTC trimer (blue), and molybdate ester (red) tribofilms (Color figure online) consistent with the molybdate ester monoblend after ten minutes. This suggests additives which deposit more Mo:S species on the surface may create more durable tribofilms. The increase in friction coefficient above base oil values upon film removal may indicate the formation of high-friction molybdenum oxides or molybdate on the surface. In the fully formulated systems (Fig. 17), there was no difference in rate of friction rise between the additives, unlike the monoblends.

\subsection{Preparation of $\mathrm{MoS}_{3}$ Decomposition Intermediate Standard}

The MoDTC trimer TEM image (Fig. 13), displayed a sulfur-rich tribofilm with amorphous and crystalline domains. As the MoDTC trimer has excess sulfur in its structure, with a $\mathrm{Mo}_{3} \mathrm{~S}_{13}$ core (Fig. 1c), it is perhaps not surprising that such a sulfur-rich film is formed upon decomposition. A series of mixed stoichiometry amorphous molybdenum sulfides are known of the form $\operatorname{MoS}_{\mathrm{x}}$. These species have been found to be effective catalysts for hydrogen evolution and have been proposed as decomposition intermediates in the formation of $\mathrm{MoS}_{2}$ from both the MoDTC dimer and molybdate ester $[15,31,39]$. One of the better known of these species is molybdenum trisulfide $\left(\mathrm{MoS}_{3}\right)$, which shares a proposed structural form with the core of the MoDTC trimer. $\mathrm{MoS}_{3}$ is proposed to exist as chains of triangular $\mathrm{Mo}_{3} \mathrm{~S}_{13}$ units joined by bridging disulfide ligands $[41,45]$. The structure of which is shown in Fig. 18.

To determine if the amorphous species observed in the TEM images was likely to be $\mathrm{MoS}_{3}$, a sample was created thermally by the thermal decomposition of ammonium tetrathiomolybdate under a nitrogen atmosphere. Ammonium tetrathiomolybdate thermally decomposes in two stages: the first at $180{ }^{\circ} \mathrm{C}$ with the release of ammonia and hydrogen sulfide to form $\mathrm{MoS}_{3}$ and a second stage at $350{ }^{\circ} \mathrm{C}$ to form $\mathrm{MoS}_{2}$ (Fig. 19) [46-48]. Each step of this reaction is accompanied by a change in mass, so the progress of the reaction can be determined by following the mass loss of the reactants. To create the $\mathrm{MoS}_{3}$ sample in this study, a sample of ammonium tetrathiomolybdate was heated under nitrogen at $240{ }^{\circ} \mathrm{C}$ for $20 \mathrm{~min}$. This was performed in a thermogravimetric analyser under a nitrogen atmosphere to ensure that the reaction stopped after the production of $\mathrm{MoS}_{3}$ and no $\mathrm{MoS}_{2}$ was formed. Figure 20 shows the first reaction step corresponding to the formation of the $\mathrm{MoS}_{3}$ decomposition intermediate. Chemical analysis of the resulting black solid was performed using Raman and XPS of the Mo 3d and S $2 \mathrm{p}$ regions. 
Fig. 18 MoDTC trimer structure (a) and structure of amorphous $\mathrm{MoS}_{3}(\mathbf{b})$

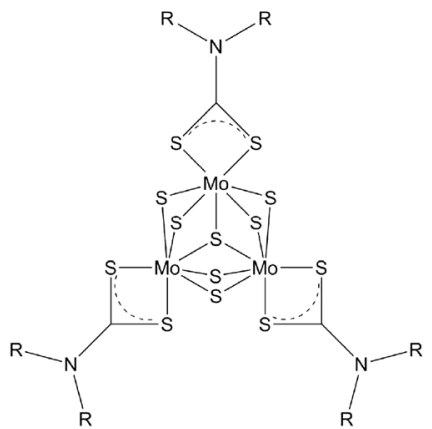

(a) MoDTC trimer

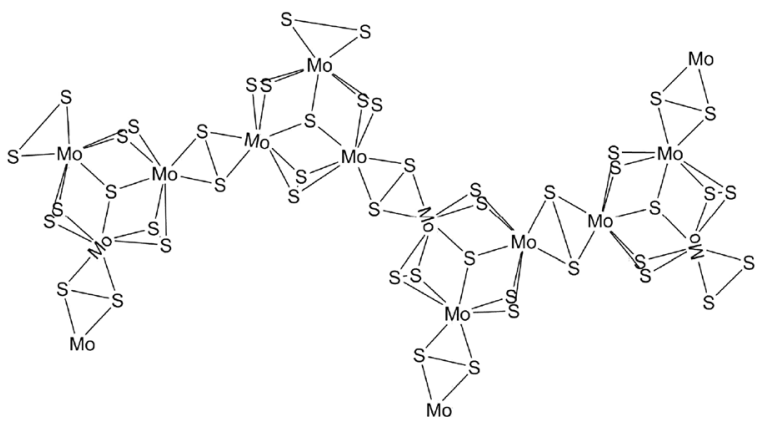

(b) $\mathrm{MoS}_{3}$ structure

$$
\left(\mathrm{NH}_{4}\right)_{2} \mathrm{MoS}_{4} \stackrel{180^{\circ} \mathrm{C}}{\longrightarrow} \mathrm{MoS}_{3}+2 \mathrm{NH}_{3}+\mathrm{H}_{2} \mathrm{~S} \stackrel{350^{\circ} \mathrm{C}}{\longrightarrow} \mathrm{MoS}_{2}+\mathrm{S}
$$

Fig. 19 Thermal decomposition mechanism of ammonium tetrathiomolybdate

To confirm that the thermal decomposition product was $\mathrm{MoS}_{3}$ and had not gone on to form crystalline $\mathrm{MoS}_{2}$, Raman spectroscopy was performed under the conditions described in Table 2, except in this instance, 20 accumulations were performed to improve the signal-to-noise ratio, as amorphous $\mathrm{MoS}_{3}$ is a poor Raman scatterer. The results are presented in Fig. 21. If crystalline $\mathrm{MoS}_{2}$ was present in the sample, the scattering peaks of $\mathrm{MoS}_{2}$ would drown out any of the $\mathrm{MoS}_{3}$ peaks. There is a peak observed in the $380 \mathrm{~cm}^{-1}$, but no corresponding peaks around $408 \mathrm{~cm}^{-1}$ which sits in the valley of the $\mathrm{MoS}_{3}$ spectrum. From this, it is concluded that there is no significant amount of crystalline $\mathrm{MoS}_{2}$ in the thermally prepared $\mathrm{MoS}_{3}$ sample. The $\mathrm{MoS}_{3}$ sample showed a strong scattering peak at $456 \mathrm{~cm}^{-1}$ corresponding to an apical Mo-S vibration. This is the most prominent of the $\mathrm{MoS}_{3}$ scattering peaks which would not be covered by the $\mathrm{MoS}_{2}$ peaks in a tribofilm spectrum.

To confirm the oxidation state distribution of the thermally prepared $\mathrm{MoS}_{3}$ sample, XPS was performed upon the powder. In Fig. 22, the $\mathrm{MoS}_{3}$ standard displayed only a Mo (IV) oxidation state and a mixture of sulfide and persulfide environments in the $S 2 p$ region. A small amount of sulfatetype $\mathrm{S}$ environment was observed at $168 \mathrm{eV}$ due to surface oxidation. The XPS assignments of the $S 2 p$ environment agree well with those of films of deposited $\mathrm{Mo}_{3} \mathrm{~S}_{13}$ clusters found in the literature $[49,50]$. The spectrum of the Mo $3 \mathrm{~d}$ environment suggests that $\mathrm{MoS}_{3}$ is a candidate for the increased amount of Mo (IV) amorphous species displayed by the MoDTC trimer in XPS (Fig. 11). $\mathrm{MoS}_{3}$ is one of a series of amorphous molybdenum sulfides which can have a Mo (IV) oxidation state [51-53]. The amorphous sulfides observed in Fig. 13 cannot be assigned the specific stoichiometry of $\mathrm{MoS}_{3}$. Instead, it would be more correct to say

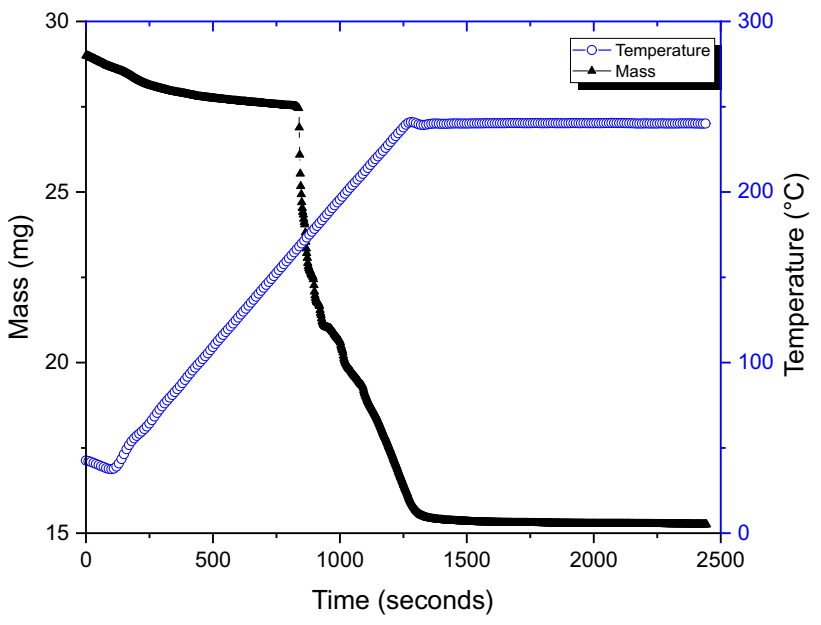

Fig. 20 Thermogravimetric analysis trace of ammonium tetrathiomolybdate for preparation of $\mathrm{MoS}_{3}$ standard

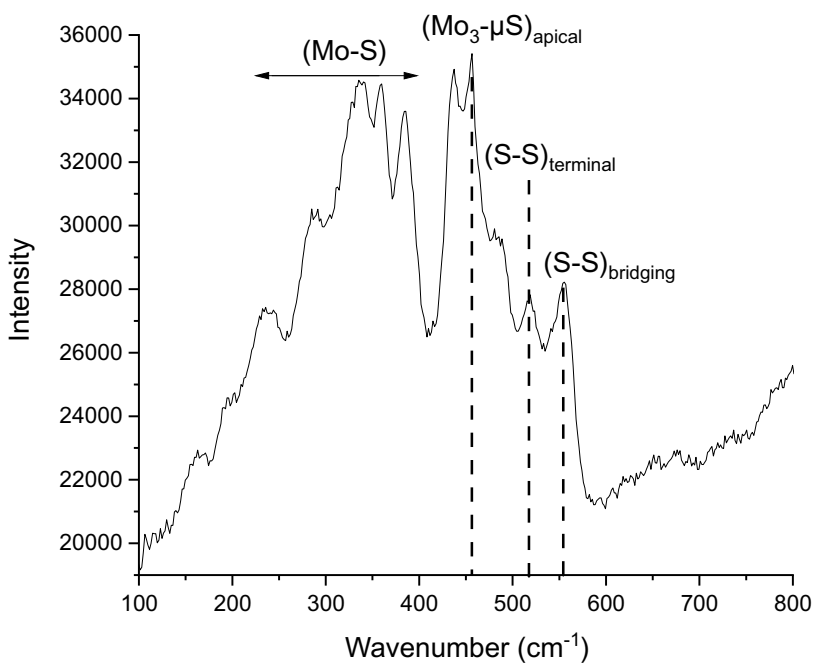

Fig. 21 Raman spectrum of $\mathrm{MoS}_{3}$ derived from the thermal decomposition of ammonium tetrathiomolybdate 

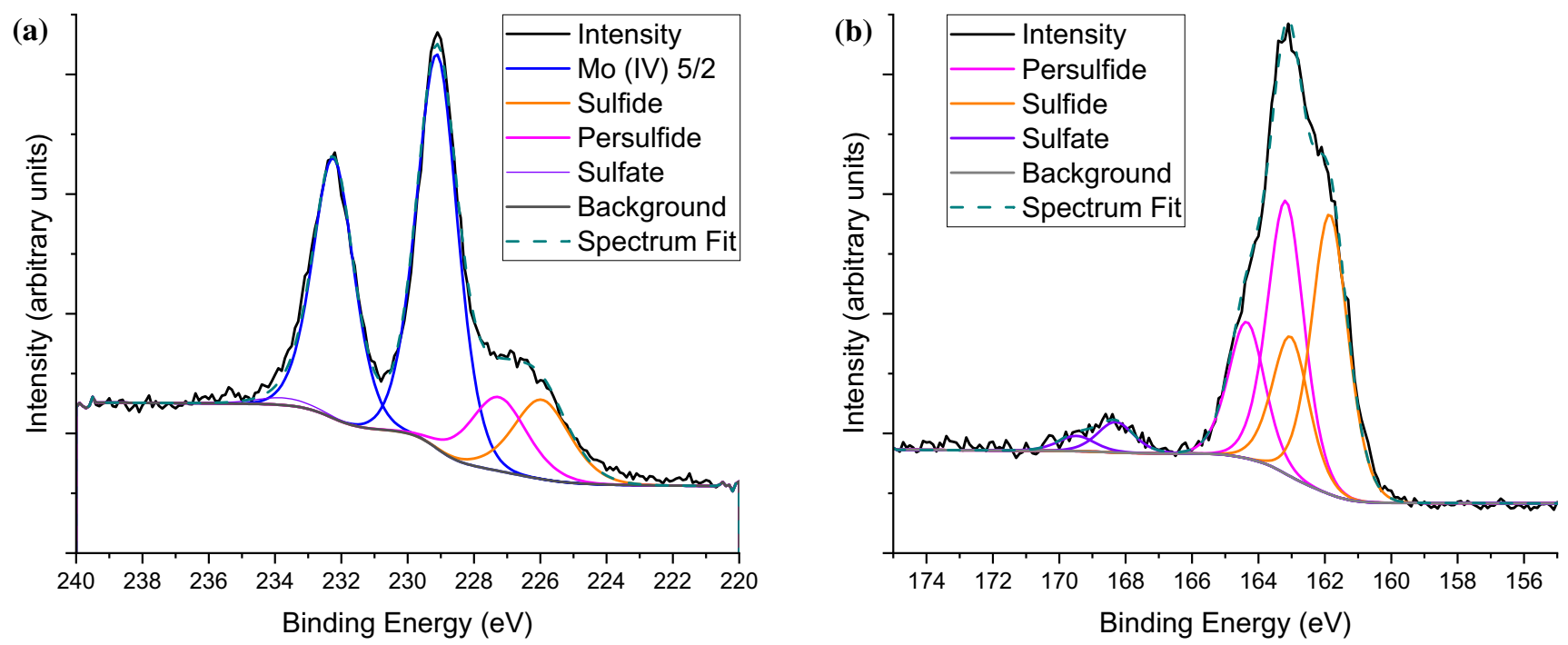

Fig. 22 Mo 3d (a) and S 2p (b) environments of $\mathrm{MoS}_{3}$ prepared from ammonium tetrathiomolybdate

that the amorphous sulfides observed are likely of the $\mathrm{MoS}_{\mathrm{x}}$ family of similarly structured compounds, of which $\mathrm{MoS}_{3}$ is the most well known.

\section{Discussion}

In fully formulated systems, all the additives displayed effective friction reduction, consistent with the formation of $\mathrm{MoS}_{2}$ (Fig. 4). Raman spectroscopy confirmed $\mathrm{MoS}_{2}$ formation, and this species contributes to the Mo (IV) peaks observed by XPS. In addition to $\mathrm{MoS}_{2}$, amorphous molybdenum sulfides were formed on the surface, along with some Mo (VI) species.

In fully formulated oil systems, the tribofilms all had similar XPS spectra in the Mo 3d region also, showing a range of Mo (IV) and Mo (VI) oxidation states. In both the fully formulated and monoblend systems, the tribofilms derived from the MoDTC trimer showed an increased proportion of Mo (IV) to Mo (VI), when compared to the Mo(IV) to $\mathrm{Mo}(\mathrm{VI})$ ratio of the other additives. The presence of Mo (VI) in the tribofilm means that the tribofilm must undergo oxidation into an oxygenated molybdenum (VI) species. Although no peaks associated with these species are present in the Raman spectra of these compounds, this does not preclude the formation of amorphous molybdenum oxides. Such oxides would not be easily detectable with Raman spectroscopy $[54,55]$. Alternatively, the Mo (VI) environment may be due to the oxidation of the top few atomic layers of the tribofilm post-test and is seen in XPS as this technique is more surface sensitive than Raman spectroscopy. In this case, oxygenated molybdenum species would not necessarily be decomposition products of the additives, but rather the result of the oxidation of the surface film when exposed to air post-test.

Despite differences in additive structure, the formulations lead to similar surface chemistry. The chemically similar natures of the films suggest that the additives form a common decomposition intermediate on the contact surface. It has been proposed that $\mathrm{MoS}_{2}$ can be formed on the surface from amorphous $\mathrm{MoS}_{3}[19,31]$. An amorphous Mo:S film can be seen from the monoblend MoDTC trimer TEM cross section (Fig. 13). $\mathrm{MoS}_{3}$ also thermally decomposes to form $\mathrm{MoS}_{2}$ [46]. $\mathrm{MoS}_{3}$ is composed of $\left(\mathrm{S}^{2-}\right)$ and $\left(\mathrm{S}_{2}{ }^{2-}\right)$ ligands bonded to a Mo center and has the same Mo $3 \mathrm{~d}$ binding energy as $\mathrm{MoS}_{2}$ [56-58]. The formation of this amorphous species may also explain the increased levels of Mo (IV) observed by XPS for the MoDTC trimer tribofilms, relative to the other additives. In addition, the dimer and trimer monoblend tribofilms, and the fully formulated oil tribofilms for all three additives display the Mo-S $\mathrm{S}_{\text {(apical) }}$ $\left(456 \mathrm{~cm}^{-1}\right)$ vibration in their Raman spectra which forms part of the $\mathrm{MoS}_{3}$ extended structures of $\mathrm{Mo}_{3} \mathrm{~S}_{13}$ unit polymers. The monoblend tribofilms also show the $\left(\mathrm{S}-\mathrm{S}_{\text {bridging }}\right)$ vibration at $555 \mathrm{~cm}^{-1}$. These vibrations are also observed in the Raman spectrum of thermally prepared $\mathrm{MoS}_{3}$ (Fig. 21). The MoDTC trimer may be more easily able to form $\mathrm{MoS}_{3}$ than the MoDTC dimer or molybdate ester as it is more sulfur rich than the other additives and less structural rearrangement is needed to form $\mathrm{MoS}_{3}$ from the MoDTC trimer. The MoDTC trimer already contains bridging sulfurs which can connect with other trimer centers in order to create a longer co-ordination polymer of $\mathrm{MoS}_{3}$. The polymerization of $\mathrm{Mo}_{3} \mathrm{~S}_{13}$ units can occur upon loss of one of the dithiocarbamate ligands of the MoDTC trimer [59]. 
The increased levels of amorphous sulfides produced by the MoDTC trimer can be seen in the monoblend FIB cross sections (Figs. 13 and 14). The MoDTC trimer produces a thicker, more consistent film than the MoDTC dimer. Computational modeling of the films expected from the two additives has been reported in the literature wherein thicker, amorphous films of pseudo- $\mathrm{MoS}_{2}$ nanoparticles derived from the MoDTC trimer are expected, in contrast to thinner two-dimensional $\mathrm{MoS}_{2}$ films from the MoDTC dimer [23]. Formation of such species may explain the increased film thickness observed for the MoDTC trimer structure as amorphous pseudo- $\mathrm{MoS}_{2}$ species are formed from this additive as opposed to thinner, two-dimensional MoDTC dimer packing structures [23].

Wear processes in the tribological tests are likely to create differences in the localized contact conditions on the asperity scale that may lead to alterations in the tribofilms formed. In order to reduce these variations caused by wear, the tribological tests were run for $2 \mathrm{~h}$ in order to have confidence in moving past the "running in" period of wear. The localized contact conditions, however, would not inherently change the chemical reactions occurring in the contact but may affect the rate at which they occur due to local flash temperature fluctuations. On the macroscale, the contact conditions are averaged out such that the mean contact experienced that would affect $\mathrm{MoS}_{2}$ distributions are those presented in Table 1.

Raman mapping showed a patchy distribution of intensities for the MoDTC dimer and MoDTC trimer in both monoblend and fully formulated systems. This is in agreement with previous mapping intensity studies [43, 60]. Previous studies have suggested that the friction performance of an additive system is closely correlated with the level of $\mathrm{MoS}_{2}$ coverage on the surface. This was not found to be the case for the molybdate ester fully formulated system [31, 60]. Figure 6 shows the molybdate ester FFO had very little surface coverage under the conditions studied but displayed the lowest friction coefficient.

The low-friction coefficient of the low coverage Molybdate Ester FFO additive and higher friction of the high coverage, thicker layer deposition of the MoDTC dimer monoblend tribofilms, therefore, appears to show that friction coefficient is unrelated to the total amount of Mo:S compound deposited on the surface. Only minimal $\mathrm{MoS}_{2}$ is required for low friction. Mere deposition of molybdenum-sulfur species on the surface is insufficient for optimal friction reduction. The species deposited must also be sufficiently crystalline. It is possible that the molybdate ester achieves this friction performance through the production of longer, more crystalline $\mathrm{MoS}_{2}$ chains, as observed by De Barros Bouchet et al. [19].

Computational modeling studies of molybdenum additive adsorption chemistry have shown that the presence of oxygen in the additive structure can improve the adsorption of the additive on iron, facilitating the molecular orientation required for $\mathrm{MoS}_{2}$ formation [61, 62]. The lack of oxygen in the sulfur-rich MoDTC trimer may encourage the formation of amorphous molybdenum sulfides, whereas the oxygenated MoDTC dimer and molybdate ester are likely to bind more favorably to the iron surface in order to decompose into well-oriented, crystalline $\mathrm{MoS}_{2}$ sheets.

The thicker deposition of Mo:S species by the MoDTC trimer allowed for tribological formation of $\mathrm{MoS}_{2}$ upon removal of the additive supply in Fig. 16. This provided a more durable level of friction reduction than the equivalent MoDTC dimer monoblend oil. This behavior is likely due to formation of crystalline $\mathrm{MoS}_{2}$ from the amorphous Mo:S thick film, as proposed by Khaemba et al. [15] and Oumahi et al. [31].

All of the fully formulated oils displayed little friction durability in Fig. 17 as the FFO $\mathrm{MoS}_{2}$ films are formed on top of the protective ZDDP layer and are likely to be thinner than the monoblend films $[19,43]$.

\section{Conclusions}

Three molybdenum friction modifier additives (MoDTC dimer, MoDTC trimer, and Molybdate ester) were subjected to tribological testing as both monoblends in base oil, and as fully formulated oil systems. The tribofilms derived from these oil systems were characterized by Raman, XPS, and FIB-TEM in order to determine if the choice of additive structure affected the characteristics of the $\mathrm{MoS}_{2}$ tribofilms formed under identical tribological conditions.

The tribofilms formed from all of the additives were chemically similar, displaying a mixture of Mo (IV) $\mathrm{MoS}_{2}$ and Mo (VI) species. The MoDTC trimer displayed a slight preference for the Mo (IV) oxidation state compared to the MoDTC dimer and the molybdate ester. This is due to greater formation of the $\mathrm{MoS}_{3}$ decomposition intermediate for the MoDTC trimer observed by TEM.

Under identical tribological conditions, the MoDTC trimer monoblend produces a consistent Mo:S layer across the surface while the MoDTC dimer monoblend produced a much thinner film that appeared patchy and was only formed on iron oxide asperities. The MoDTC trimer produced a thicker Mo:S film because of its structural similarity to the amorphous $\mathrm{MoS}_{3}$ decomposition intermediate. The thicker film formed from the MoDTC trimer monoblend led to longer friction reduction durability of this additive relative to that of the MoDTC dimer as amorphous molybdenum sulfides already deposited on the surface can form $\mathrm{MoS}_{2}$ for a short time after the additive supply is removed. This suggests that film thickness may be the primary determinant of low-friction durability. 
It is clear from the analysis of the films that despite there being little chemical difference observable by Raman and XPS between the films formed from the additives, there are notable differences in film thickness, Mo oxidation state distribution, and surface coverage. The surface coverage of $\mathrm{MoS}_{2}$ is not the primary determinant of friction coefficient. This is shown by contrast of the MoDTC dimer and molybdate ester FFOs. The MoDTC trimer displays high $\mathrm{MoS}_{2}$ surface coverage but does not provide a friction coefficient as low as the $\mathrm{MoS}_{2}$ derived from the molybdate ester at much lower levels of $\mathrm{MoS}_{2}$ surface coverage.

The design of the molecular additives and their interactions with other additives in the formulation have an observable effect on the characteristics of the $\mathrm{MoS}_{2}$ films formed under identical film formation conditions.

Acknowledgements The authors thank Dr. Andrew Britton of the Versatile X-ray Spectroscopy Facility (VXSF) at the University of Leeds for their support \& assistance in this work. The EPSRC and Infineum UK are gratefully acknowledged for their support of this work.

Open Access This article is licensed under a Creative Commons Attribution 4.0 International License, which permits use, sharing, adaptation, distribution and reproduction in any medium or format, as long as you give appropriate credit to the original author(s) and the source, provide a link to the Creative Commons licence, and indicate if changes were made. The images or other third party material in this article are included in the article's Creative Commons licence, unless indicated otherwise in a credit line to the material. If material is not included in the article's Creative Commons licence and your intended use is not permitted by statutory regulation or exceeds the permitted use, you will need to obtain permission directly from the copyright holder. To view a copy of this licence, visit http://creativecommons.org/licenses/by/4.0/.

\section{References}

1. Holmberg, K., Erdemir, A.: The impact of tribology on energy use and $\mathrm{CO} 2$ emission globally and in combustion engine and electric cars. Tribol. Int. 135, 389-396 (2019). https://doi.org/10.1016/j. triboint.2019.03.024

2. Holmberg, K., Erdemir, A.: Influence of tribology on global energy consumption, costs and emissions. Friction 5, 263-284 (2017). https://doi.org/10.1007/s40544-017-0183-5

3. Wong, V.W., Tung, S.C.: Overview of automotive engine friction and reduction trends-effects of surface, material, and lubricantadditive technologies. Friction 4, 1-28 (2016). https://doi.org/10. 1007/s40544-016-0107-9

4. Song, I., Park, C., Choi, H.C.: Synthesis and properties of molybdenum disulphide: from bulk to atomic layers. RSC Adv. 5, 74957514 (2015). https://doi.org/10.1039/C4RA11852A

5. Serpini, E., Rota, A., Valeri, S., Polcar, T., Nicolini, P., Ukraintsev, E.: Tribology international nanoscale frictional properties of ordered and disordered MoS 2. Tribiol. Int. 136, 67-74 (2019). https://doi.org/10.1016/j.triboint.2019.03.004

6. Khaemba, D.N., Neville, A., Morina, A.: A methodology for Raman characterisation of MoDTC tribofilms and its application in investigating the influence of surface chemistry on friction performance of MoDTC lubricants. Tribol. Lett. 59, 1-17 (2015). https://doi.org/10.1007/s11249-015-0566-6
7. Okubo, H., Yonehara, M., Sasaki, S.: In situ Raman observations of the formation of MoDTC-derived tribofilms at steel/steel contact under boundary lubrication. Tribol. Trans. 61, 1040-1047 (2018). https://doi.org/10.1080/10402004.2018.1462421

8. Ponjavic, A., Lemaigre, T., Southby, M., Spikes, H.A.: Influence of NOxand air on the ageing behaviour of MoDTC. Tribol. Lett. 65, 1-7 (2017). https://doi.org/10.1007/s11249-017-0836-6

9. De Feo, M., Minfray, C., De Barros Bouchet, M.I., Thiebaut, B., Martin, J.M.: MoDTC friction modifier additive degradation: correlation between tribological performance and chemical changes. RSC Adv. 5, 93786-93796 (2015). https://doi.org/10.1039/c5ra1 $5250 \mathrm{j}$

10. De Feo, M., Minfray, C., De Barros Bouchet, M.I., Thiebaut, B., Le Mogne, T., Vacher, B., Martin, J.M.: Ageing impact on tribological properties of MoDTC-containing base oil. Tribol. Int. 92, 126-135 (2015). https://doi.org/10.1016/j.triboint.2015.04.014

11. Grossiord, C., Varlot, K., Martin, J., Mogne, T.L., Esnouf, C.: MoS2 single sheet lubrication by molybdenum. Tribol. Int. 31, 737-743 (1998)

12. De Barros Bouchet, M.I., Martin, J.M., Le Mogne, T., Bilas, P., Vacher, B., Yamada, Y.: Mechanisms of MoS2 formation by MoDTC in presence of ZnDTP: effect of oxidative degradation. Wear 258, 1643-1650 (2005). https://doi.org/10.1016/j.wear. 2004.11.019

13. Graham, J., Spikes, H., Korcek, S.: The friction reducing properties of molybdenum dialkyldithiocarbamate additives: part I-factors influencing friction reduction. Tribol. Trans. 44, 626-636 (2001). https://doi.org/10.1080/10402000108982504

14. Okubo, H., Tadokoro, C., Sasaki, S.: In situ Raman-SLIM monitoring for the formation processes of MoDTC and ZDDP tribofilms at steel/steel contacts under boundary lubrication. Tribol. Online 15, 105-116 (2020). https://doi.org/10.2474/trol.15.105

15. Khaemba, D.N., Neville, A., Morina, A.: New insights on the decomposition mechanism of molybdenum dialkyldithiocarbamate (MoDTC): a Raman spectroscopic study. RSC Adv. 6, 38637-38646 (2016). https://doi.org/10.1039/C6RA00652C

16. Gorbatchev, O., De Barros Bouchet, M.I., Martin, J.M., Léonard, D., Le-Mogne, T., Iovine, R., Thiebaut, B., Héau, C.: Friction reduction efficiency of organic Mo-containing FM additives associated to ZDDP for steel and carbon-based contacts. Tribol. Int. 99, 278-288 (2016). https://doi.org/10.1016/j.triboint.2016.03. 035

17. Haque, T., Morina, A., Neville, A., Kapadia, R., Arrowsmith, S.: Effect of oil additives on the durability of hydrogenated DLC coating under boundary lubrication conditions. Wear 266, 147-157 (2009). https://doi.org/10.1016/j.wear.2008.06.011

18. Haque, T., Morina, A., Neville, A., Kapadia, R., Arrowsmith, S.: Non-ferrous coating/lubricant interactions in tribological contacts: assessment of tribofilms. Tribol. Int. 40, 1603-1612 (2007). https://doi.org/10.1016/j.triboint.2007.01.023

19. De Barros Bouchet, M.I., Martin, J.M., Oumahi, C., Gorbatchev, O., Afanasiev, P., Geantet, C., Iovine, R., Thiebaut, B., Heau, C.: Booster effect of fatty amine on friction reduction performance of Mo-based additives. Tribol. Int. 119, 600-607 (2018). https:// doi.org/10.1016/j.triboint.2017.11.039

20. Stiefel, E.I., McConnachie, J.M. and Leta, D.P., "Method for Enhancing and Restoring Reduction Friction Effectiveness", U.S. Patent 5,888,945 (1999)

21. Waddoups, M., Hartley, R.J. and Miyoshi, T., "Lubricating Oil Composition Containing Two Molybdenum Additives", U.S. Patent 6,074,993 (2000)

22. Hartley, R.J., Waddoups, M., Bell, I.A.W., Bidwell, T.R., Farnsworth, G.R. and Miyoshi, T., "Lubricating Oil Composition", U.S. Patent 6,300,291 B1 (2001)

23. Pawlicki, A.A., Bansal, D.G., Borodinov, N., Belianinov, A., Cogen, K., Clarke, D., Sumpter, B.G., Ovchinnikova, O.S.: In situ 
multimodal imaging for nanoscale visualization of tribofilm formation. J. Appl. Phys. (2020). https://doi.org/10.1063/1.5140480

24. Stiefel, E.I., McConnachie, J.M., Leta, D.P., Francisco, M.A., Coyle, C.L., Guzi, P.J. and Pictroski, G.G., "Trinuclear Molybdenum Multifunctional Additive For Lubricating Oils", U.S. Patent 6,232,276 B1 (2001)

25. Price, J.A. and Neblett, R.F., "Preparation of Glycol Molybdate Complexes", U.S. Patent 3,285,942 (1966)

26. Coupland, K. and Smith, C.R., "Organo Molybdenum Friction Reducing Antiwear Additives", U.S. Patent 4,164,473 (1979)

27. Rowan, E.V., Karol, T.J. and Farmer, H.H., "Organic Molybdenum Complexes" U.S. Patent 4,889,647 (1985)

28. Karol, T.J., "Organic Molybdenum Complexes" U.S. Patent 5,137,647 (1992)

29. Chinas-Castillo, F., Lara-Romero, J., Alonso-Núñez, G., Barceinas-Sánchez, J.D.O., Jiménez-Sandoval, S.: Friction reduction by water-soluble ammonium thiometallates. Tribol. Lett. 26, 137-144 (2007). https://doi.org/10.1007/s11249-006-9179-4

30. Chiñas-Castillo, F., Lara-Romero, J., Alonso-Núñez, G., Barceinas-Sánchez, J.D.D.O., Jiménez-Sandoval, S.: MoS 2 films formed by in-contact decomposition of water-soluble tetraalkylammonium thiomolybdates. Tribol. Lett. 29, 155-161 (2008). https://doi.org/10.1007/s11249-007-9292-z

31. Oumahi, C., De Barros-Bouchet, M.I., Le Mogne, T., Charrin, C., Loridant, S., Geantet, C., Afanasiev, P., Thiebaut, B.: MoS2 formation induced by amorphous $\mathrm{MoS} 3$ species under lubricated friction. RSC Adv. 8, 25867-25872 (2018). https://doi.org/10. 1039/c8ra03317j

32. Miklozic, K.T., Graham, J., Spikes, H.: Chemical and physical analysis of reaction films formed by molybdenum dialkyl-dithiocarbamate friction modifier additive using Raman and atomic force microscopy. Tribol. Lett. 11, 71-81 (2001). https://doi.org/ 10.1023/A:1016655316322

33. Sherwood, P.M.A.: The use and misuse of curve fitting in the analysis of core X-ray photoelectron spectroscopic data. Surf. Interface Anal. 51, 589-610 (2019). https://doi.org/10.1002/sia. 6629

34. Choi, J., Thompson, L.T.: XPS study of as-prepared and reduced molybdenum oxides. Appl. Surf. Sci. 93, 143-149 (1996)

35. Lichtman, D., Craig, J.H., Sailer, V., Drinkwine, M.: AES and XPS spectra of sulfur in sulfur compounds. Appl. Surf. Sci. 7, 325-331 (1981). https://doi.org/10.1016/0378-5963(81)90080-5

36. Ganta, D., Sinha, S., Haasch, R.T.: 2-D material molybdenum disulfide analyzed by XPS. Surf. Sci. Spectra 21, 19-27 (2014). https://doi.org/10.1116/11.20140401

37. Tang, M.L., Grauer, D.C., Lassalle-Kaiser, B., Yachandra, V.K., Amirav, L., Long, J.R., Yano, J., Alivisatos, A.P.: Structural and electronic study of an amorphous MoS3 hydrogen-generation catalyst on a quantum-controlled photosensitizer. Angew. Chem. Int. Ed. 50, 10203-10207 (2011). https://doi.org/10.1002/anie. 201104412

38. Merki, D., Fierro, S., Vrubel, H., Hu, X.: Amorphous molybdenum sulfide films as catalysts for electrochemical hydrogen production in water. Chem. Sci. 2, 1262-1267 (2011). https://doi.org/ $10.1039 / \mathrm{c} 1 \mathrm{sc} 00117 \mathrm{e}$

39. Lee, C.H., Lee, S., Lee, Y.K., Jung, Y.C., Ko, Y.I., Lee, D.C., Joh, H.I.: Understanding the origin of formation and active sites for thiomolybdate [Mo3S13]2- clusters as hydrogen evolution catalyst through the selective control of sulfur atoms. ACS Catal. 8, 5221-5227 (2018). https://doi.org/10.1021/acscatal.8b01034

40. Chang, C.H., Chan, S.S.: Infrared and Raman studies of amorphous MoS3 and poorly crystalline MoS2. J. Catal. 72, 139-148 (1981). https://doi.org/10.1016/0021-9517(81)90085-3

41. Tran, P.D., Tran, T.V., Orio, M., Torelli, S., Truong, Q.D., Nayuki, K., Sasaki, Y., Chiam, S.Y., Yi, R., Honma, I., Barber, J., Artero, V.: Coordination polymer structure and revisited hydrogen evolution catalytic mechanism for amorphous molybdenum sulfide. Nat. Mater. 15, 640-646 (2016). https://doi.org/10.1038/ nmat4588

42. Spevack, P.A., McIntyre, N.S.: A Raman and XPS investigation of supported molybdenum oxide thin films. 2. Reactions with hydrogen sulfide. J. Phys. Chem. 97, 11031-11036 (1993). https://doi. org/10.1021/j100144a021

43. Rai, Y., Neville, A., Morina, A.: Transient processes of MoS2 tribofilm formation under boundary lubrication. Lubr. Sci. 28, 449-471 (2016)

44. Morina, A., Neville, A.: Understanding the composition and low friction tribofilm formation/removal in boundary lubrication. Tribol. Int. 40, 1696-1704 (2007). https://doi.org/10.1016/j.triboint. 2007.02.001

45. Fu, W., Yang, S., Yang, H., Guo, B., Huang, Z.: 2D amorphous MoS 3 nanosheets with porous network structures for scavenging toxic metal ions from synthetic acid mine drainage. J. Mater. Chem. A 7, 18799-18806 (2019). https://doi.org/10.1039/c9ta0 5861c

46. Brito, J.L., Ilija, M., Hernández, P.: Thermal and reductive decomposition of ammonium thiomolybdates. Thermochim. Acta $\mathbf{2 5 6}$ 325-338 (1995)

47. Walton, R.I., Dent, A.J., Hibble, S.J.: In situ investigation of the thermal decomposition of ammonium tetrathiomolybdate using combined time-resolved X-ray absorption spectroscopy and X-ray diffraction. Chem. Mater. 10, 3737-3745 (1998). https://doi.org/ $10.1021 / \mathrm{cm} 980716 \mathrm{~h}$

48. Poisot, M., Bensch, W., Fuentes, S., Alonso, G.: Decomposition of tetra-alkylammonium thiomolybdates characterised by thermoanalysis and mass spectrometry. Thermochim. Acta. 444, 35-45 (2006). https://doi.org/10.1016/j.tca.2006.02.025

49. Yue, D., Qian, X., Zhang, Z., Kan, M., Ren, M., Zhao, Y.: CdTe/ $\mathrm{CdS}$ core/shell quantum dots cocatalyzed by sulfur tolerant [Mo 3 S 13 ] 2- nanoclusters for efficient visible-light-driven hydrogen evolution. ACS Sustain. Chem. Eng. 4, 6653-6658 (2016). https:// doi.org/10.1021/acssuschemeng.6b01520

50. Hellstern, T.R., Kibsgaard, J., Tsai, C., Palm, D.W., King, L.A., Abild-Pedersen, F., Jaramillo, T.F.: Investigating catalyst-support interactions to improve the hydrogen evolution reaction activity of thiomolybdate [Mo3S13]2- nanoclusters. ACS Catal. 7, 71267130 (2017). https://doi.org/10.1021/acscatal.7b02133

51. Benck, J.D., Chen, Z., Kuritzky, L.Y., Forman, A.J., Jaramillo, T.F.: Amorphous molybdenum sul fi de catalysts for electrochemical hydrogen production: insights into the origin of their catalytic activity. ACS Catal. 2(9), 1916-1923 (2012). https://doi.org/10. $1021 / \mathrm{cs} 300451 \mathrm{q}$

52. Liang, K.S., deNaufville, J.P., Jacobson, A.J., Chianelli, R.R., Betts, F.: Structure of amorphous transition metal sulfides. J. Non Cryst. Solids. 35-36, 1249-1254 (1980). https://doi.org/10.1016/ 0022-3093(80)90369-5

53. Tang, M.L., Grauer, D.C., Lassalle-kaiser, B., Yachandra, V.K., Amirav, L., Long, J.R., Yano, J., Alivisatos, A.P.: Structural and electronic study of an amorphous MoS 3 hydrogen- generation catalyst on a quantum-controlled photosensitizer. Angew. Chem. 123, 10385-10389 (2011). https://doi.org/10.1002/ange.20110 4412

54. Camacho-López, M.A., Haro-Poniatowski, E., Lartundo-Rojas, L., Livage, J., Julien, C.M.: Amorphous-crystalline transition studied in hydrated MoO3. Mater. Sci. Eng. B 135, 88-94 (2006). https:// doi.org/10.1016/j.mseb.2006.08.041

55. Ajito, K., Nagahara, L.A., Tryk, D.A., Hashimoto, K., Fujishima, A.: Study of the photochromic properties of amorphous MoO3 films using Raman microscopy. J. Phys. Chem. 99, 16383-16388 (1995). https://doi.org/10.1021/j100044a028 
56. Weber, T., Muijsers, J.C., Niemantsverdriet, J.W.: Structure of amorphous MoS3. J. Phys. Chem. 99, 9194-9200 (1995). https:// doi.org/10.1021/j100022a037

57. Cao, P., Peng, J., Liu, S., Cui, Y., Hu, Y., Chen, B., Li, J., Zhai, M.: Tuning the composition and structure of amorphous molybdenum sulfide/carbon black nanocomposites by radiation technique for highly efficient hydrogen evolution. Sci. Rep. 7, 1-11 (2017). https://doi.org/10.1038/s41598-017-16015-y

58. Hibble, S.J., Wood, G.B.: Modeling the structure of amorphous MoS3: a neutron diffraction and reverse Monte Carlo study. J. Am. Chem. Soc. 126, 959-965 (2004). https://doi.org/10.1021/ja037 6660

59. Tran, P.D., Duong, T.M., Nguyen, P.D., Nguyen, A.D., Le, L.T., Nguyen, L.T., Pham, H.V.: Insights into the electrochemical polymerization of [Mo3S13]2- generating amorphous molybdenum sulfide. Chemistry (2019). https://doi.org/10.1002/chem. 201903098
60. Xu, D., Wang, C., Espejo, C., Wang, J., Neville, A., Morina, A.: Understanding the friction reduction mechanism based on molybdenum disulfide tribofilm formation and removal. Langmuir 34, 13523-13533 (2018). https://doi.org/10.1021/acs.langmuir.8b023 29

61. Peeters, S., Restuccia, P., Loehlé, S., Thiebaut, B., Righi, M.C.: Characterization of molybdenum dithiocarbamates by first-principles calculations. J. Phys. Chem. A 123, 7007-7015 (2019). https://doi.org/10.1021/acs.jpca.9b03930

62. Peeters, S., Restuccia, P., Loehlé, S., Thiebaut, B., Righi, M.C.: Tribochemical reactions of MoDTC lubricant additives with iron by quantum mechanics/molecular mechanics simulations. J. Phys. Chem. C (2020). https://doi.org/10.1021/acs.jpcc.0c02211

Publisher's Note Springer Nature remains neutral with regard to jurisdictional claims in published maps and institutional affiliations. 